\title{
A Numerical Study on the Effects of Taiwan Topography on a Convective Line during the Mei-Yu Season
}

\author{
CHUNG-CHIEH WANG* \\ Department of Environmental Management, Jin-Wen Institute of Technology, Taipei, Taiwan \\ George TAi-Jen Chen \\ Department of Atmospheric Sciences, National Taiwan University, Taipei, Taiwan \\ TZu-Chin CHen \\ Department of Atmospheric Sciences, National Taiwan University, and Central Weather Bureau, Taipei, Taiwan \\ KAZUHISA TSUBOKI \\ Hydrospheric Atmospheric Research Center, Nagoya University, Nagoya, Japan
}

(Manuscript received 21 October 2004, in final form 11 April 2005)

\begin{abstract}
During the morning hours on 23 May 2002, a convective line associated with a mei-yu front brought heavy rainfall along the coast of central Taiwan under favorable synoptic conditions of warm air advection and large convective available potential energy (CAPE) of over $3000 \mathrm{~m}^{2} \mathrm{~s}^{-2}$. Doppler radar observations indicated that deep convection was organized into a linear shape with a northeast-southwest orientation along the front about $70 \mathrm{~km}$ offshore from Taiwan over the northern Taiwan Strait. The system then moved toward Taiwan at a slow speed of about $4 \mathrm{~m} \mathrm{~s}^{-1}$. In the present study, the effects of Taiwan topography on this convective line and subsequent rainfall distribution were investigated through numerical modeling using the Nagoya University Cloud-Resolving Storm Simulator (CReSS) at a 2-km horizontal grid size. Experiments with different terrain heights of Taiwan, including full terrain (FTRN), half terrain (HTRN), and no terrain (NTRN), were performed. The control run using full-terrain and cold rain explicit microphysics realistically reproduced the evolution of the convective line and the associated weather with many fine details.

Two low-level convergence zones were found to be crucial in the development of this convective line and the subsequent rainfall distribution over Taiwan. The first was along the mei-yu front and forced mainly by the front, but was terrain enhanced off the northwestern coast of Taiwan due to the blocking of air on the windward side of the Central Mountain Range (CMR). After formation, convective cells along this zone propagated southeastward and produced rainfall over the northwestern coast. As the front moved closer to Taiwan, a second arc-shaped convergence zone with a nearly north-south orientation along about $120^{\circ} \mathrm{E}$ formed ahead of the front between the prevailing flow and near-surface offshore flow induced by the blocking. This second zone was terrain induced, and convection initiated near its northern end was found to be responsible for the rainfall maximum observed near the coast of central Taiwan. Its intensity and position were highly sensitive to terrain height. In the HTRN run where the terrain was reduced by half, a weaker zone closer to the CMR (by about $50 \mathrm{~km}$ ) was produced, and the rain fell mostly over the windward slope of the terrain instead of over the coastal plain. When the terrain was removed in the NTRN run, no such zone with the correct orientation formed. It was also found that the frontal movement near northern Taiwan was slightly delayed with the presence of terrain, and this affected the timing and distribution of local rainfall during the later stages of this event.
\end{abstract}

* Current affiliation: Department of Atmospheric Sciences, Chinese Culture University, Taipei, Taiwan.

Corresponding author address: Prof. George Tai-Jen Chen, Department of Atmospheric Sciences, National Taiwan University, No. 61, Ln. 144, Sec. 4, Keelung Rd., Taipei 10772, Taiwan.

E-mail: george@george2.as.ntu.edu.tw

(C) 2005 American Meteorological Society 


\section{Introduction}

There are different mechanisms capable of organizing deep convection into a linear shape in the atmosphere. These, among others, include synoptic-scale forcing by fronts (e.g., Carbone 1982; Browning 1990) and by mesoscale topography (Smolarkiewicz et al. 1988). Sufficiently strong vertical wind shear also provides convection with a means of self-organization in the absence of other forcing (e.g., Bluestein and Jain 1985; Houze et al. 1990; LeMone et al. 1998). The topographical effect on flow structure, convection, and the subsequent rainfall distribution over regions with high terrain has received much attention in recent years. In the low Froude number $(\mathrm{Fr}=U / N h$, where $U$ is the speed of wind perpendicular to mountain, $N$ is the buoyancy oscillation frequency, and $h$ is the terrain height, respectively) regime $(\mathrm{Fr}<1)$, the blocking effect is significant (Pierrehumbert 1984; Blumen 1990; Baines 1995) and can influence upstream to a distance limited by the Rossby radius of deformation $\left(L_{R}=\right.$ $N h / f$, where $f$ is the Coriolis parameter, Pierrehumbert and Wyman 1985). Under such conditions, windwardside ridging, leeside troughing, and flow deflection occur (e.g., Smith 1982; Banta 1990; Overland and Bond 1995), often leading to offshore convergence and convection, and the formation of coastal jets (Grossman and Durran 1984; Doyle 1997; Braun et al. 1997; Chien et al. 2001; Colle et al. 2002). In addition, as a front approaches, terrain blocking can cause frontal deformation and delay its movement (Braun et al. 1997; Neiman et al. 2004). The amount and distribution of rainfall, often an issue of focus over flood-prone mountainous regions, is also affected by the blocking effect. During the eighth Intensive Observing Period (IOP 8) case in the Mesoscale Alpine Program (MAP) conducted over northern Italy in 1999, in which $\mathrm{Fr}<1$, the stable low-level southerly flow was blocked by the Alps and only a less than expected amount of rain was received over the windward-side slopes (Bousquet and Smull 2003; Steiner et al. 2003). In contrast, the MAP IOP $2 b$ event occurred under a high Fr regime $(\mathrm{Fr}>1)$, and the strong, unblocked, and conditionally unstable low-level flow was forced to ascend the mountain slope to produce heavy rainfall (Rotunno and Ferretti 2003; Medina and Houze 2003).

Over the Taiwan area, complex interaction between fronts, convection, environmental flow, and topography also often occurs during the mei-yu season from midMay to mid-June (e.g., Kuo and Chen 1990; Chen 1992; Lin 1993). Although the Central Mountain Range (CMR) is only about $100 \mathrm{~km}$ in width, its mean elevation of $2.5 \mathrm{~km}$ makes it a common occurrence for the flow to be in a low Fr (i.e., flow around) regime with significant blocking effect (e.g., Li and Chen 1998; Wang and Chen 2003). Using $N \sim 10^{-2} \mathrm{~s}^{-1}$ and $f \sim 6 \times$ $10^{-5} \mathrm{~s}^{-1}$ at $25^{\circ} \mathrm{N}$, a typical $L_{R}$ of CMR is estimated to be about $415 \mathrm{~km}$. The topographical effect on coastal rainfall during IOP 3 of the Taiwan Area Mesoscale Experiment (TAMEX; Kuo and Chen 1990) in 1987 was investigated by Yeh and Chen (2002). Using the fifth-generation Pennsylvania State University-National Center for Atmospheric Research (PSU-NCAR) Mesoscale Model (MM5), they found that the offshore convergence enhanced by the terrain's blocking effect under prevailing southwesterly flow was essential for the localized rainfall maximum along the northwestern coast of Taiwan.

During the morning hours on 23 May 2002, a convective line developed over northern Taiwan Strait along the mei-yu front and brought heavy rainfall to coastal areas from central to northwestern Taiwan. Doppler radar observations indicated that this line strengthened and became better organized at about 70 $\mathrm{km}$ offshore before it made landfall (to be further described in section 3). Since the location is prone to terrain-induced low-level convergence, one wonders whether a process similar to the one in the TAMEX IOP 3 case was also involved, and what its exact role was in this event. Therefore, we were motivated to carry out the present study through model simulation. Since ice processes are often important in such events (e.g., Richard et al. 2003), the Cloud-Resolving Storm Simulator (CReSS) with explicit treatment in cloud microphysics at high resolution was used (section 4). As will be shown later, our results reveal important topographical impacts that take place in this case. By comparing with Yeh and Chen (2002), this study also sheds additional insights into the effects of Taiwan topography on convection and precipitation.

\section{Data and analysis}

\section{a. Observational data and analysis}

Six-hourly gridded regional objective analyses from the Japanese Meteorological Agency (JMA) at $0.25^{\circ}$ latitude-longitude resolution at 20 levels during 22-23 May 2002 were used for synoptic discussion and to compare with model output. The regional analysis is performed by the JMA regional spectral model (RSM) using a miltivariate three-dimensional (3D) optimum interpolation (OI) method to combine first-guess fields with observations that are free of internal/external quality control problems (Segami et al. 1989; Onogi 1998) from a variety of platforms (Tsuyuki and Fujita 
2002). Sounding data at 0200 LST 23 May (i.e., 1800 UTC 22 May) at Makung, Taiwan $\left(23.7^{\circ} \mathrm{N}, 119.6^{\circ} \mathrm{E}\right)$ were used to evaluate thermodynamic conditions of the prefrontal environment.

To examine the evolution of the convection and precipitation, hourly vertical maximum-echo indicator (VMI) radar reflectivity composites and total rainfall from gauge network during 22-23 May 2002 in the Taiwan area, both provided by the Central Weather $\mathrm{Bu}$ reau of Taiwan were used. These maps will also be used to verify the control experiment performed by CReSS. In addition, hourly surface observations at several sites over Taiwan during the case period were employed to analyze the weather phenomena associated with the passage of the convective line, but no map of this sort will be presented.

\section{b. Data for model simulation}

The JMA global objective analyses at $1.25^{\circ}$ latitudelongitude resolution at 14 levels (from 1000 to $50 \mathrm{hPa}$ ) were used to provide initial and lateral boundary conditions to the CReSS model. Global instead of regional analyses were chosen so that small features were absent in the initial field, a condition better suited for examining the pure effects of terrain under a given synoptic condition. Also available every $6 \mathrm{~h}$, the global analyses were produced by the JMA global spectral model (GSM) using 3D variational method with the incremental approach (Kanamitsu et al. 1983; Courtier et al. 1994; Tsuyuki and Fujita 2002).

A terrain data file at $1-\mathrm{km}$ resolution was used for the lower boundary of the model, but values outside the island of Taiwan were interpolated from a 9-km East Asian terrain file. Using the JMA global analyses, the CReSS model was initialized at 2000 LST (1200 UTC) 22 May 2002, and sensitivity tests with different terrain heights of Taiwan were conducted. Further description of the model and experiment design will be given in section 4 .

\section{Synoptic setup and case evolution}

\section{a. Synoptic condition}

In this section, we first describe the synoptic condition under which the convective line developed. Figure 1 presents the JMA regional analysis $\left(0.25^{\circ}\right)$ from 925 to $500 \mathrm{hPa}$ at $2000 \mathrm{LST}$ (1200 UTC) $22 \mathrm{May} 2002$. At $925 \mathrm{hPa}$, high pressure systems were located over the interior of China to the northwest and over the Pacific to the southeast (Fig. 1a). Between the two highs, a wind-shift line extended west-southwestward from the low near $29^{\circ} \mathrm{N}, 128^{\circ} \mathrm{E}$ to $26^{\circ} \mathrm{N}, 120^{\circ} \mathrm{E}$, then to $22^{\circ} \mathrm{N}$, $113^{\circ} \mathrm{E}$ along the southeastern coast of China. The line also defines the position of the mei-yu front since horizontal wind shear rather than thermal gradient is often the more significant attribute of a mei-yu front over Taiwan and southern China (e.g., Akiyama 1973; Chen and Chang 1980; Kato 1985). Northerly flow existed behind the front while southwesterly flow of about 10 $\mathrm{m} \mathrm{s}^{-1}$ prevailed immediately ahead of the front over the Taiwan Strait, with stronger winds (shaded) off northwestern and southeastern Taiwan (Fig. 1a). Thus, the 925-hPa wind field around Taiwan in the $0.25^{\circ} \mathrm{JMA}$ analysis already bares characteristics typical of barrier influences ( $\mathrm{Li}$ and Chen 1998). The pressure pattern remained the same at $850 \mathrm{hPa}$, while the wind shift line was slightly to the north with west-southwesterly flow ahead (Fig. 1b). The flow over northern Taiwan Strait was weaker than at $925 \mathrm{hPa}$, indicating that the stronger winds near the surface were indeed linked to terrain blocking. The wind shift line was no longer visible at $700 \mathrm{hPa}$, while a north-south-oriented shortwave trough was passing $115^{\circ} \mathrm{E}$ (Fig. 1c). Westerly flow of about $10 \mathrm{~m} \mathrm{~s}^{-1}$ prevailed from southern China to Taiwan, and the veering of winds with height near Taiwan indicated the existence of warm air advection (WAA) and synoptic-scale ascent. At $500 \mathrm{hPa}$ (Fig. 1d), winds were west-northwesterly over Taiwan Strait, with stronger westerly flow $\left(\geq 20 \mathrm{~m} \mathrm{~s}^{-1}\right)$ north of $32^{\circ} \mathrm{N}$ near the Korean Peninsula together with tighter geopotential height gradients. The same pattern remained farther aloft at $300 \mathrm{hPa}$ (not shown).

When both wind and relative vorticity $(\zeta)$ in the JMA regional analysis are examined, the position and movement of the mei-yu front near Taiwan can be determined. At 2000 LST 22 May, the $950-\mathrm{hPa}$ front was right along the southeastern coast of China, with a maximum vorticity of more than $2.0 \times 10^{-4} \mathrm{~s}^{-1}$ (Fig. 2a). The southwesterly flow over northern Taiwan Strait was $15 \mathrm{~m} \mathrm{~s}^{-1}$ at $950 \mathrm{hPa}$, and there existed a pair of anticyclonic/cyclonic vorticity centers along the windward/leeward sides of the CMR. The mei-yu front had moved offshore from southeastern China at 0200 LST 23 May (not shown). Six hours later at 0800 LST (Fig. 2b), the front was within 30 (90) km from northern (central) Taiwan, and the section east of Taiwan appeared to have already moved southward. Thus, in this particular case the (synoptic scale) front approached northern to central Taiwan at a speed of about 2.5$3.5 \mathrm{~m} \mathrm{~s}^{-1}$.

The thermodynamic condition in the prefrontal environment is presented in Fig. 3, plotted using an upper-air sounding launched at Makung (near $23.7^{\circ} \mathrm{N}$, 
(a) $\quad 5 / 222000$ LST $925 \mathrm{hPa}$

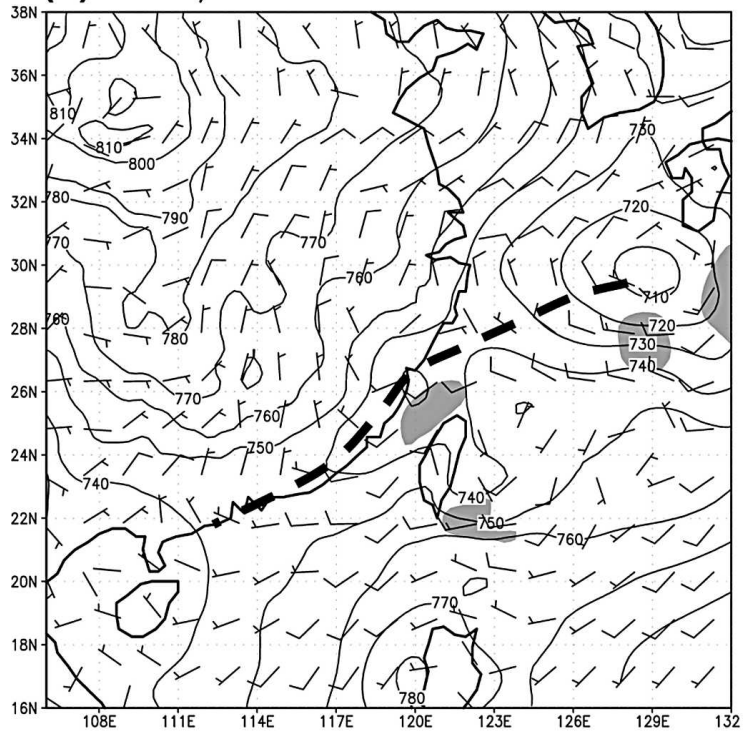

(c) $\quad 5 / 222000$ LST $700 \mathrm{hPa}$

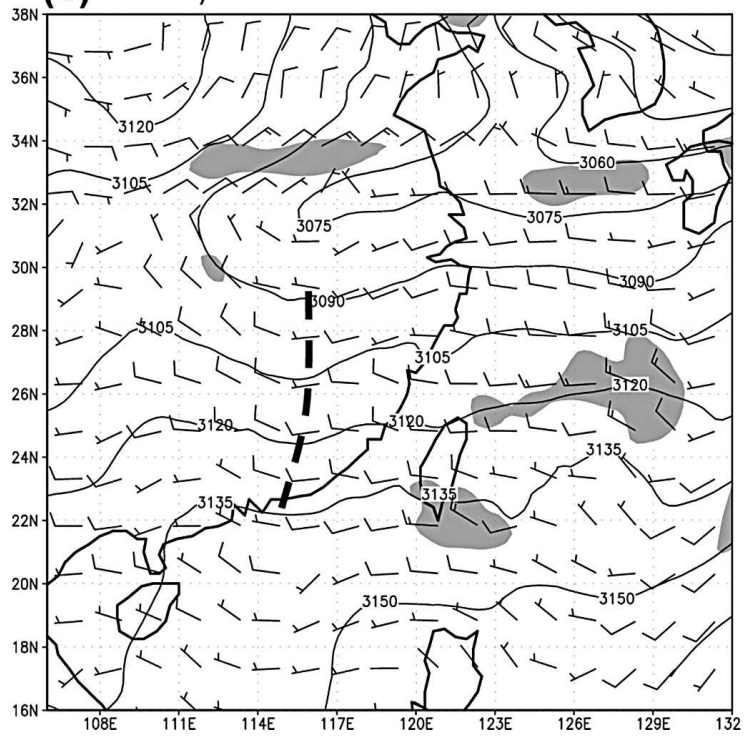

(b) $\quad 5 / 222000$ LST $850 \mathrm{hPa}$
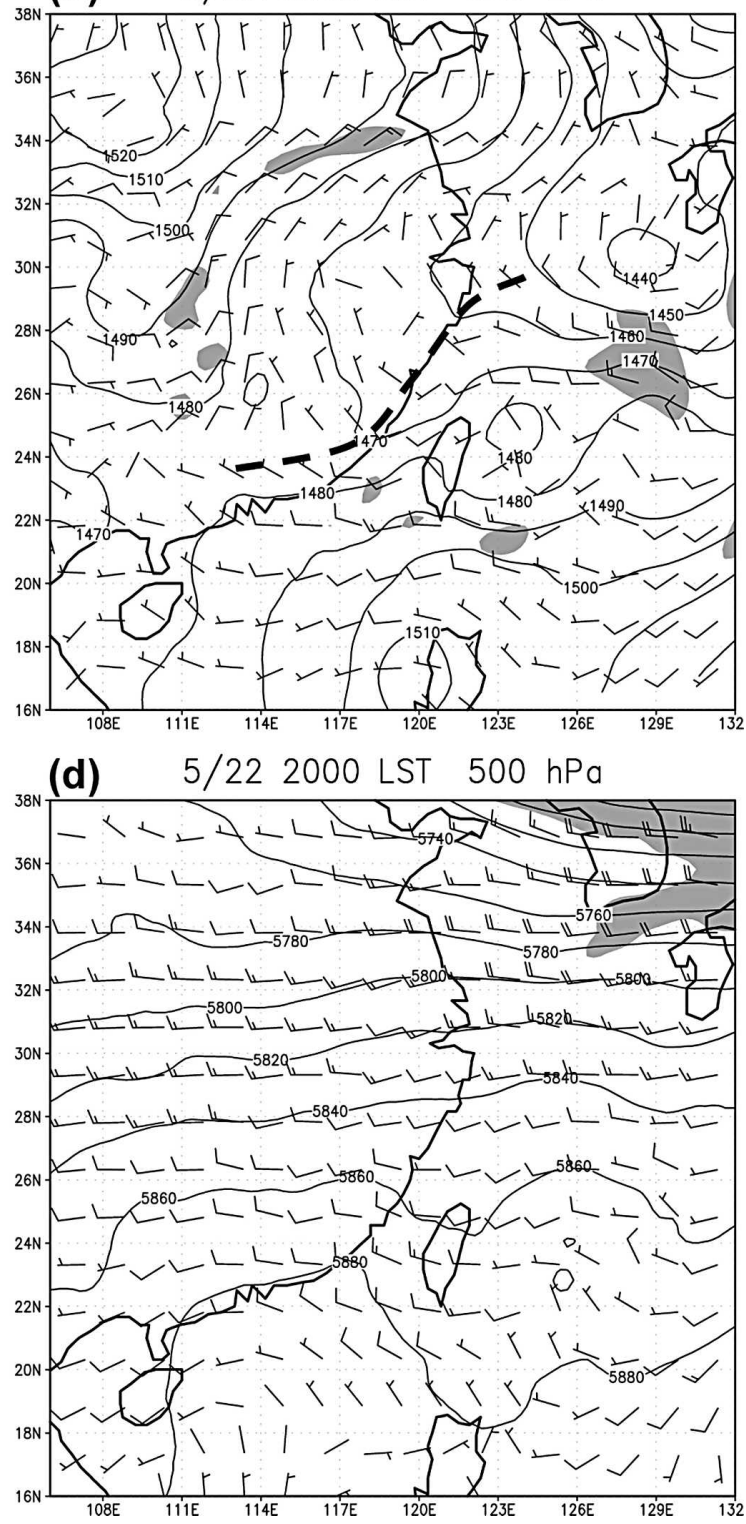

FIG. 1. JMA regional analysis $\left(0.25^{\circ}\right.$ resolution) at 2000 LST (1200 UTC) 22 May 2002 at (a) 925, (b) 850, (c) 700, and (d) 500 hPa. Geopotential heights (contours) were analyzed at intervals of (a) 10, (b) 10, (c) 15, and (d) 20 gpm. For winds, full (half) barbs are 10 (5) $\mathrm{m} \mathrm{s}^{-1}$, and areas with wind speed $\geq 12.5 \mathrm{~m} \mathrm{~s}^{-1}$ in (a)-(c) and $20 \mathrm{~m} \mathrm{~s}^{-1}$ in (d) are shaded. Thick dashed lines depict the position of mei-yu front, wind shift line, or trough.

$119.6^{\circ}$ E; cf. Fig. 2a) at 0200 LST 23 May. The air was conditionally unstable and very moist below $700 \mathrm{hPa}$, yielding a very large convective available potential energy (CAPE) of $3114.3 \mathrm{~m}^{2} \mathrm{~s}^{-2}$ and a very small convective inhibition (CIN) of $1.7 \mathrm{~m}^{2} \mathrm{~s}^{-2}$ for an air parcel at the surface. The vertical wind profile also indicated both WAA at lower levels and considerable westnorthwesterly wind shear between 950 and $500 \mathrm{hPa}$ (Fig. 3). Thus, the prefrontal environment of the approaching mei-yu front in the Taiwan area was favor- able for deep convection development, while no significant feature existed in the upper troposphere.

\section{b. Evolution of the convective line}

Figure 4 presents hourly composites of VMI radar reflectivity $(\mathrm{dBZ})$ in the Taiwan area for $0000-0500$ LST 23 May 2002. A series of convective cells first formed over northern Taiwan Strait near 0000 LST and aligned roughly parallel to the mei-yu front, in a northeast-southwest direction from about $27.0^{\circ} \mathrm{N}, 122.1^{\circ} \mathrm{E}$ to 
(a)

$$
5 / 222000 \text { LST } 950 \mathrm{hPa}
$$

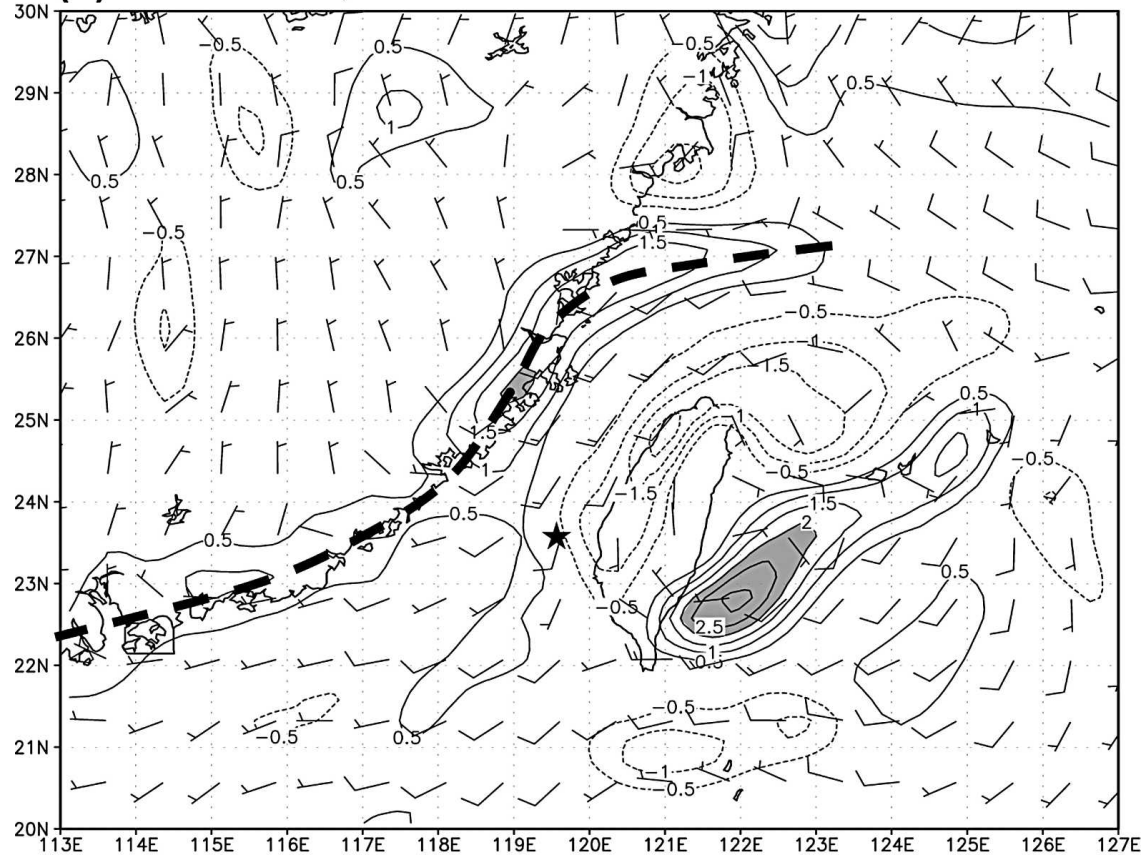

(b)

$5 / 230800$ LST $950 \mathrm{hPa}$

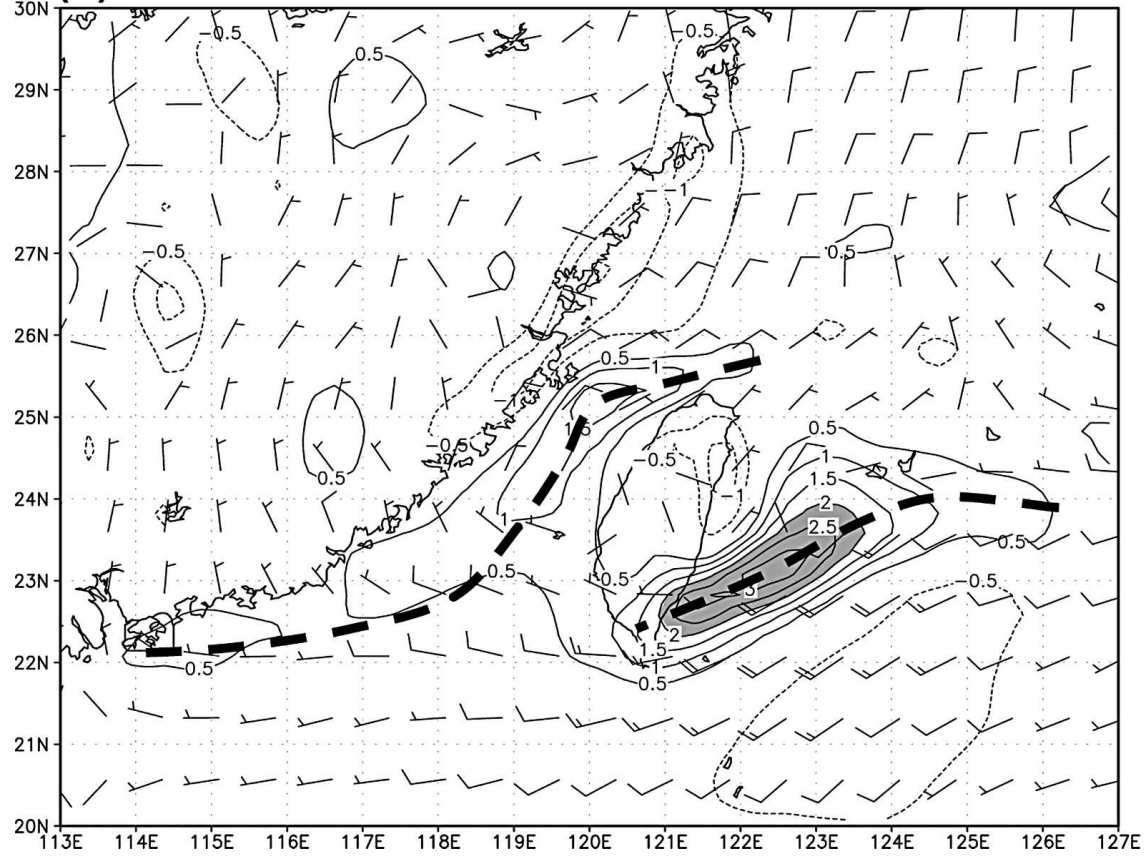

FIG. 2. The 950 -hPa JMA regional analysis $\left(0.25^{\circ}\right.$ resolution $)$ of winds and relative vorticity $\left(10^{-4} \mathrm{~s}^{-1}\right)$ at (a) 2000 LST (1200 UTC) 22 May and (b) 0800 LST (0000 UTC) 23 May 2002. For winds, full (half) barbs are $10(5) \mathrm{m} \mathrm{s}^{-1}$. Relative vorticity is analyzed at intervals of 0.5 $\times 10^{-4} \mathrm{~s}^{-1}$ (dashed for negative values and zero line omitted), and areas $\geq 2.0 \times 10^{-4} \mathrm{~s}^{-1}$ are shaded. Thick dashed lines depict the position of mei-yu front, and the asterisk in (a) marks the sounding station Makung (46734). 


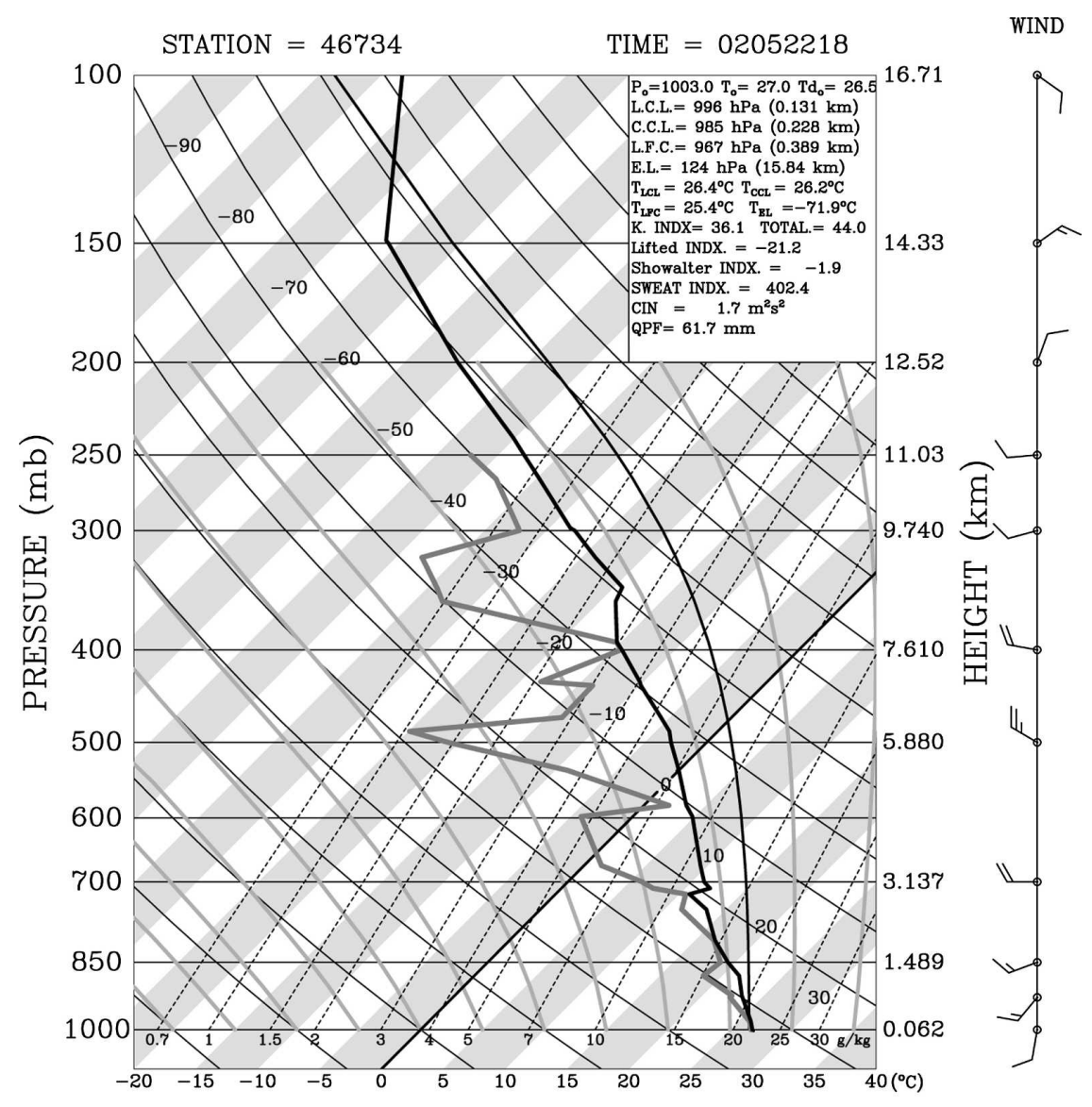

SKEW T, log P DIAGRAM

FIG. 3. Skew $T-\log p$ diagram for the sounding taken at Makung station $\left(46734\right.$; near $23.7^{\circ} \mathrm{N}$, $119.6^{\circ} \mathrm{E}$, see Fig. 2a for location) at 0200 LST 23 (1800 UTC 22) May 2002. CAPE and CIN for an air parcel at the surface were 3114.3 and $1.7 \mathrm{~m}^{2} \mathrm{~s}^{-2}$, respectively.

$25.6^{\circ} \mathrm{N}, 119.6^{\circ} \mathrm{E}$ (Fig. 4a). Over the next $3 \mathrm{~h}$, these cells gradually intensified while moving slowly southeastward. They became organized into a convective line with scattered new development over the prefrontal area over the northern Taiwan Strait and just north of Taiwan (Figs. 4b-d). The system as a whole matured at $0400 \mathrm{LST}$ as the region $\geq 20 \mathrm{dBZ}$ reached a length of roughly $430 \mathrm{~km}$ and a width of $20-90 \mathrm{~km}$. Individual cells, each about $10-25 \mathrm{~km}$ in size, were embedded inside the line (Fig. 4e). Using the criteria of Chen and Chou (1993), this system qualified as a squall line. The convective line made landfall over central Taiwan shortly after 0500 LST (Fig. 4f), then weakened significantly and dissipated after 0700 LST (not shown). Thus, the life span of this system was about $7 \mathrm{~h}$ and the propagation speed was rather uniform at about $4 \mathrm{~m} \mathrm{~s}^{-1}$, roughly in phase with the front but significantly slower than most other squall lines observed during TAMEX (Chen and Chou 1993).
The southward extension of the line over northern Taiwan Strait started near $24.8^{\circ} \mathrm{N}, 120.1^{\circ} \mathrm{E}$ at $0100 \mathrm{LST}$, about $80 \mathrm{~km}$ south of the western end of the original line (Fig. 4b). New cells continued to appear at both the northeastern and southwestern ends of the line at about $70 \mathrm{~km}$ off the coast of northwestern-central Taiwan, eventually forming the main body of the southern section by 0300 LST (Figs. 4c,d). During this process, a clear southward extension of the convective line took place, from about $24.8^{\circ}$ to almost $23.1^{\circ} \mathrm{N}$ at $0500 \mathrm{LST}$ (Fig. 4f). Thus, the system became stronger and better structured at about $70 \mathrm{~km}$ offshore before moving onshore. The (smoothed) total rainfall caused by the event between 0000 and 1000 LST (Fig. 5) reached 85 $\mathrm{mm}$ over the coastal plain of central Taiwan, and 55 and $45 \mathrm{~mm}$ over coastal regions in northern and southern Taiwan, respectively. At Wuchi station (cf. Fig. 5), nearly $100 \mathrm{~mm}$ of convective rain was received within $2 \mathrm{~h}$ during 0600-0800 LST (not shown). Since the rain 
(a) 0000 LST 23 May 2002

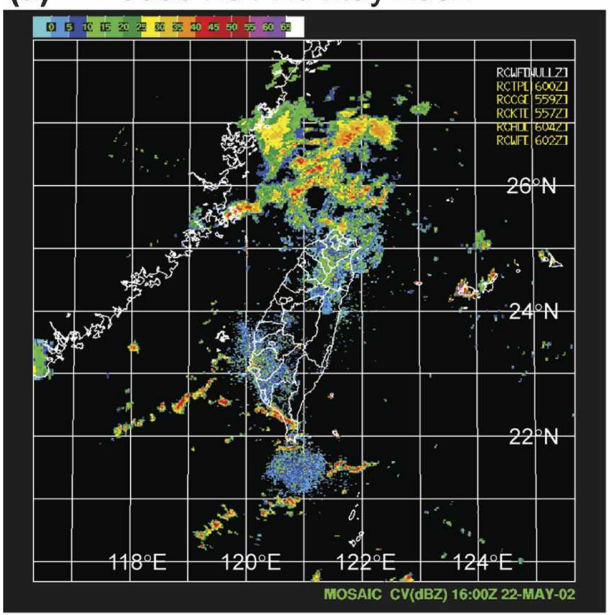

(c) 0200 LST 23 May 2002

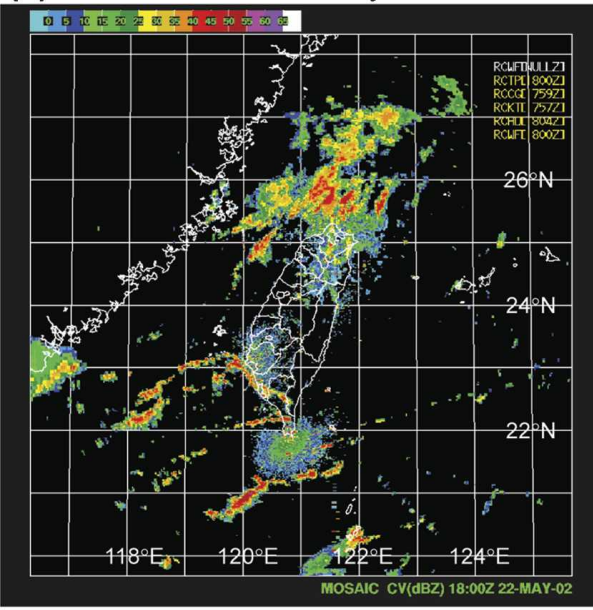

(e) 0400 LST 23 May 2002

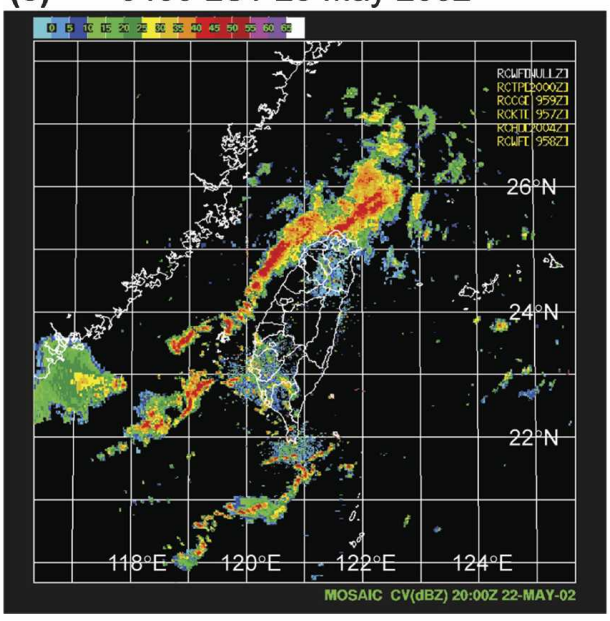

(b) 0100 LST 23 May 2002

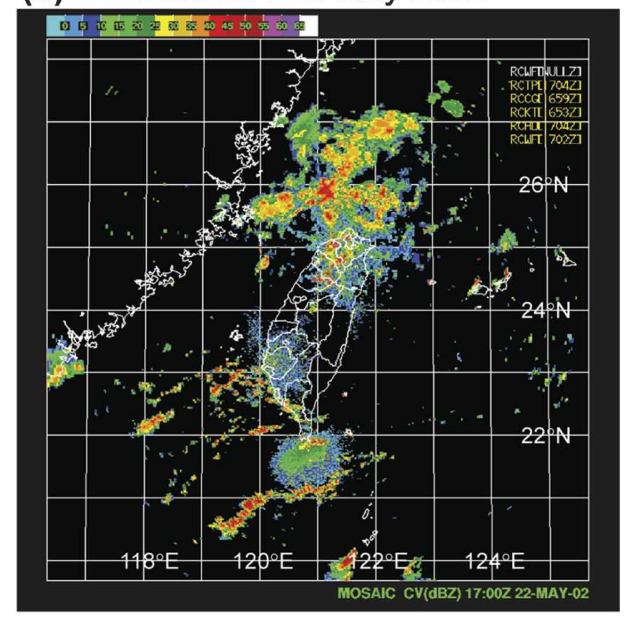

(d) 0300 LST 23 May 2002

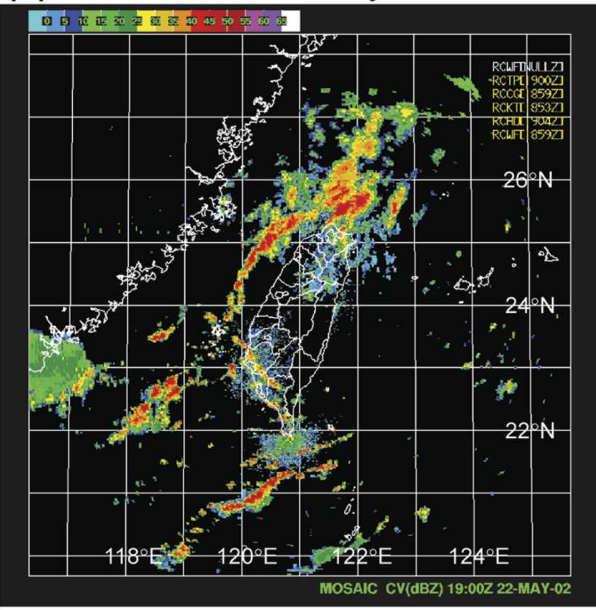

(f) 0500 LST 23 May 2002

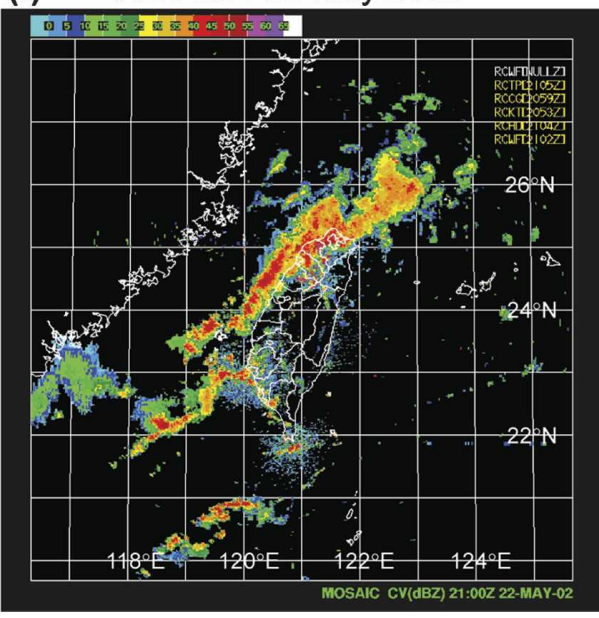

FIG. 4. Composite VMI radar reflectivity (dBZ) over Taiwan area at 1-h intervals from (a) 0000 to (f) 0500 LST 23 May 2002. Colors of shades are indicated at the top of each panel. 


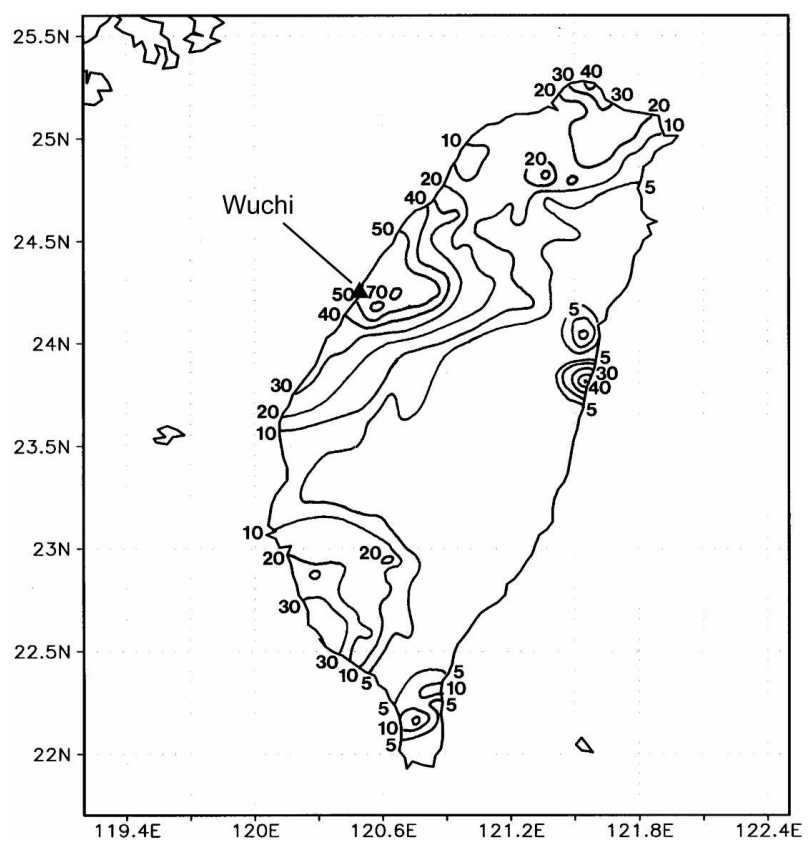

FIG. 5. Accumulated rainfall $(\mathrm{mm})$ distribution in $0000-1000$ LST 23 May 2002. The triangle marks the location of Wuchi station.

mostly fell near the coast instead of the windward slope of the CMR (cf. Fig. 6a), the distribution was a direct result of the intensification of the convective line about $70 \mathrm{~km}$ offshore from northwestern Taiwan. As mentioned in section 1, this region of intensification was collocated with that of low-level convergence induced by terrain blocking (Yeh and Chen 2002). The present study attempts to answer the questions of whether the Taiwan topography played some role in the development and evolution of this particular case, and if so, how the convective line was influenced.

\section{Model description and experiments}

\section{a. CReSS}

To investigate the role of Taiwan topography in this convective line case, the CReSS model (multiprocessor version 1.4), developed by the Hydrospheric Atmospheric Research Center (HyARC) of Nagoya University, Japan (Tsuboki and Sakakibara 2002), was used to carry out experiments using different terrain heights. This model employs fully compressible, nonhydrostatic dynamics, and is designed to realistically simulate mesoscale systems at high resolution using explicit cloud microphysics. The Cartesian coordinate $(x, y)$ in the horizontal and a terrain-following curvilinear coordinate $(\zeta)$ in the vertical directions are used, such that

$$
\zeta(x, y, z)=\frac{z_{t}\left[z-z_{s}(x, y)\right]}{z_{t}-z_{s}(x, y)},
$$

where $z_{t}$ and $z_{s}$ are model heights at the top and surface, respectively. With this coordinate system, the equations for 3D momentum, pressure, and potential temperature $(\theta)$ are formulated as described in detail by Tsuboki and Sakakibara (2002). The equation set includes all types of waves, such as Rossby waves, acoustic waves, and gravity waves. Final variables predicted are $3 \mathrm{D}$ wind components $(u, v$, and $w)$ and pressure and potential temperature perturbations ( $p^{\prime}$ and $\theta^{\prime}$ ) from the mean state, which is in hydrostatic equilibrium at the starting time of model integration.

To properly simulate clouds at fine resolution, explicit microphysics for bulk cold rain processes based on Lin et al. (1983), Cotton et al. (1986), Murakami (1990), Ikawa and Saito (1991), and Murakami et al. (1994) are used in CReSS without cumulus parameterization. A total of six species (water vapor, cloud, ice, rain, snow, and graupel) are considered, and their mixing ratio $\left(q_{x}\right.$, where the subscript $x$ denotes a species) predicted. Microphysical processes for nucleation (condensation) include deposition or sorption, condensation freezing, homogeneous, contact, and secondary nucleation (of ice crystals). Also included are deposition, evaporation, and sublimation for water vapor, melting, freezing, falling out, collection, conversion, and aggregation for other species, and shedding of liquid water (Tsuboki and Sakakibara 2002). A bulk warm rain scheme that includes only the three warm species is also available in CReSS, but only the cold rain scheme was used in this study.

Subgrid-scale turbulent mixing is parameterized using a 1.5-order closure with turbulent kinetic energy (TKE) prediction (Tsuboki and Sakakibara 2001). Planetary boundary layer (PBL) processes are parameterized largely following Mellor and Yamada (1974) as well as Segami et al. (1989). Surface fluxes of momentum and energy, and radiation processes are included (Kondo 1976; Louis et al. 1981; Segami et al. 1989) with a substrate model for ground temperature prediction, but cloud radiation is neglected. Different land-use types were not considered and evapotranspiration efficiency and albedo were fixed at 0.5 and 0.2 , respectively. For simplicity, a constant sea surface temperature of $25^{\circ} \mathrm{C}$, close to the climatological mean in the vicinity of Taiwan for May, was used over the ocean.

For numerical computation in CReSS, the Arakawa-C staggering grid and the Lorenz grid are used for discretization in the horizontal and vertical, respectively. To improve computational efficiency, a modesplitting technique (Klemp and Wilhelmson 1978) is 

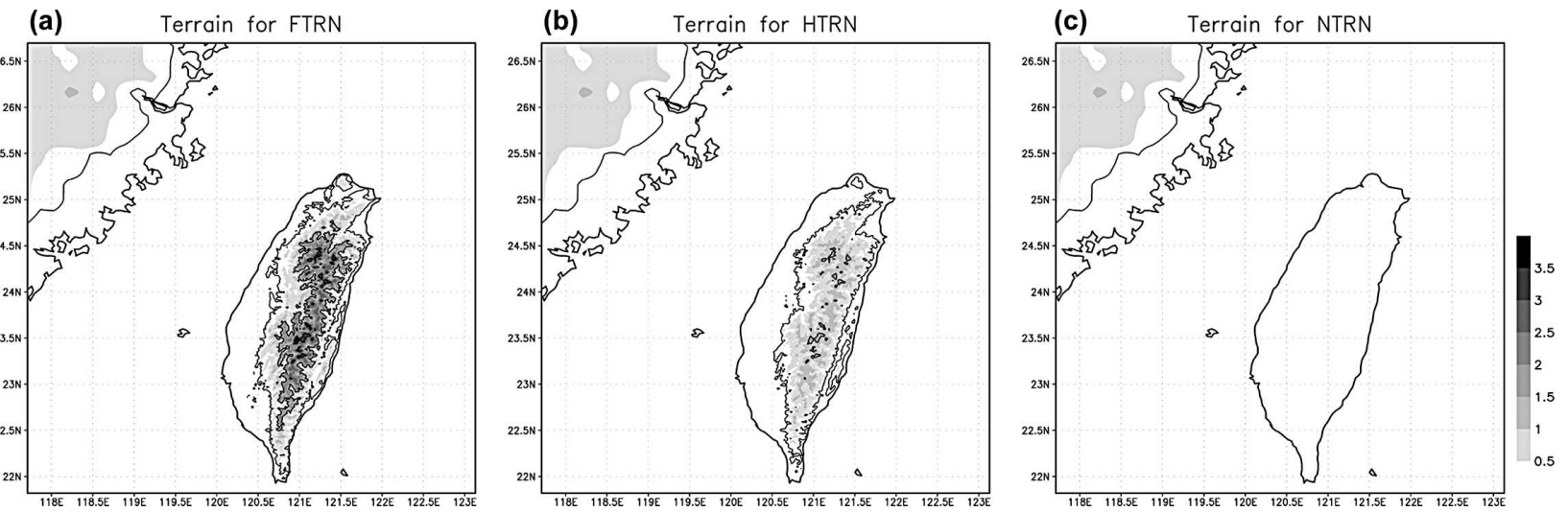

FIG. 6. The CReSS model simulation domain and different terrain height (km) of Taiwan used in the sensitivity test. (a) FTRN using actual topography of Taiwan, (b) HTRN where the topography of Taiwan was reduced by 1/2, and (c) NTRN where a flat topography of $1 \mathrm{~m}$ was used for Taiwan. Shadings are at $0.5-\mathrm{km}$ intervals as indicated at the lower right of (c), and additional contour lines at 0.2 , 1.5 , and $3 \mathrm{~km}$ are drawn.

adopted to integrate acoustic mode terms (and gravity mode by option) using a smaller time step $\Delta \tau$, and terms of all other modes using a larger time step $\Delta t$. The leapfrog scheme with the Asselin time filter (Asselin 1972) is used for time stepping, while the CrankNicolson scheme can be used to solve $p^{\prime}$ and $w$ implicitly in the vertical for small $\Delta \tau$ by option. Computational mixing is used to remove grid-scale noise. For parallel computing, data exchange between individual processing elements is performed by the Massage Passing Interface (MPI). Still under continuous development, the CReSS model has been applied to successfully simulate cloud streets during a cold air outbreak (Liu et al. 2004), localized heavy rainfall (Tsuboki 2004), and the inner structure of a typhoon (Oh et al. 2004), but not terrain-forced flow (in the formal literature) until this study. For a more complete description of the formulation and different configurations and options of CReSS, readers are referred to Tsuboki and Sakakibara (2001, 2002).

\section{b. Design of model experiments}

The CReSS model domain in the present study was set to $21.8^{\circ}-26.7^{\circ} \mathrm{N}, 117.7^{\circ}-123.1^{\circ} \mathrm{E}$ (Fig. 6) with a $2-\mathrm{km}$ horizontal grid size. A total of 60 levels were used in the vertical, stretching from a spacing of $150 \mathrm{~m}$ at the bottom to $450 \mathrm{~m}$ at a model top of $21 \mathrm{~km}$, such that the total number of grid points were $272 \times 272 \times 60$. As mentioned, all experiments were initialized at 2000 LST 22 May 2002, that is, about $4 \mathrm{~h}$ before line formation, using the $1.25^{\circ} \mathrm{JMA}$ global analysis and terrain data. Lateral boundaries were driven by interpolated conditions from successive analyses $6 \mathrm{~h}$ apart without nesting. At model top and bottom, boundary conditions were set to zero gradient and rigid surface, respectively. Each run was integrated for $18 \mathrm{~h}$ using the bulk cold rain microphysics and time steps of 2.0 (large) and $0.5 \mathrm{~s}$ (small) with output every $30 \mathrm{~min}$.

To investigate the role of Taiwan topography in the development of the current convective line, the following experiments were preformed. The first is the fullterrain run (FTRN) that used the real terrain and served as the control experiment. The second is the half-terrain run (HTRN) where the topography of Taiwan was reduced by half from the actual height while everything else remained unchanged. The third is named the no-terrain (NTRN) run, in which the entire island of Taiwan was set to $1 \mathrm{~m}$ in elevation but landsea attributes remained the same. Thus, the highest peak of CMR exceeded $3.5 \mathrm{~km}$ in FTRN and was about $1.8 \mathrm{~km}$ in HTRN runs, while no peak existed in the NTRN run (Fig. 6). An additional run without the island of Taiwan altogether (NLND) was also performed for comparison. At the starting time of the model, the JMA analysis (1000-50 $\mathrm{hPa}$ ) was interpolated onto the model grid without special treatment. Because the analyzed fields must be already affected by real terrain (or the one in GSM), no data nudging in the interior of the model domain was employed once the forward integration began.

\section{Model results}

\section{a. The FTRN experiment}

In the FTRN run using the full terrain (and other experiments), near-surface features associated with the terrain of Taiwan and southeastern China, such as local convergence, were well developed and remained quasi 
steady by 2200 LST 22 May. Therefore, even though the starting time of the model was only about $4 \mathrm{~h}$ earlier than the development of the convective line, spin up did not seem to affect the results in any serious manner. Figure 7 presents the simulated wind and relative vorticity at $378 \mathrm{~m}$ (level 3) in the FTRN run. As the mei-yu front (thick dashed) defined by the wind shift line moved off the southeastern coast of China at 0000 LST 22 May, vorticity first intensified $\left(2 \times 10^{-4} \mathrm{~s}^{-1}\right)$ along an east-west narrow zone near $26.1^{\circ} \mathrm{N}$ over northern Taiwan Strait (Fig. 7a). As this zone developed through 0200 LST, another vorticity belt with a northeastsouthwest orientation started to form to the southwest along the leading edge of the front. This vorticity belt further strengthened and extended in length when the prefrontal southwesterly flow off northwestern Taiwan increased to over $15 \mathrm{~m} \mathrm{~s}^{-1}$ (Figs. 7b,c). Upon approaching Taiwan at $0300 \mathrm{LST}$, at about $75 \mathrm{~km}$ from the coastline, the new frontal vorticity zone continued to intensify (Fig. 7d). Individual centers of 3-4 $\times 10^{-3} \mathrm{~s}^{-1}$ about $20-40 \mathrm{~km}$ in scale formed along the new frontal zone, while the first zone weakened. At 0400 LST, the length of the zone reached about $370 \mathrm{~km}$ and its width was still very narrow, only about $15 \mathrm{~km}$ (Fig. 7e). The peak intensity occurred at 0500 LST with several vorticity centers $>5 \times 10^{-3} \mathrm{~s}^{-1}$ (Fig. 7f). These $\zeta$ values were on the same order as those obtained by Lin et al. (1992) for the TAMEX IOP-13 case using Doppler radar data on a $1-\mathrm{km}$ grid. During this period as the front approached Taiwan, vorticity also started to increase along an arc-shaped boundary near $120^{\circ} \mathrm{E}$ between the prefrontal flow and the southerly (offshore) flow originating from the southern CMR. As the front continued to move southeastward at 0600 LST, the flow between the northwestern coast of Taiwan and the front weakened, while the frontal vorticity also reduced with increasing deformation in shape (Fig. $7 \mathrm{~g}$ ). The southern end of the band nonetheless extended to about $23.6^{\circ} \mathrm{N}$, also in good agreement with radar data. The front eventually reached the coast of both northern and central Taiwan at 0700 LST (Fig. 7h), and continued to weaken afterward (not shown). The front propagated in the FTRN run at a speed of about $3.5-5 \mathrm{~m} \mathrm{~s}^{-1}$, which was faster than that in the analysis (Fig. 2), but agreed very well with the traveling speed of the convective line in Fig. 4. Although the model domain was only $542 \mathrm{~km} \times$ $542 \mathrm{~km}$ without an outer domain (Fig. 6), results in Fig. 7 (and other figures to be shown) suggest that lateral boundaries driven by 6-h analyses possibly exerted only a minimal negative impact since the phenomena of interest mostly occurred near the center of the domain and were well simulated. During the case period, the cyclonic vorticity center to the southeast of Taiwan, with a maximum value of $\sim 7.5 \times 10^{-4} \mathrm{~s}^{-1}$, was also reproduced (Fig. 7). However, this feature will not be elaborated extensively since it is not our main focus.

The simulated streamlines and convergence at $687 \mathrm{~m}$ (level 5) in the FTRN run are shown in Fig. 8, which gives an overall evolution similar to Fig. 7. When the northeast-southwest line associated with low-level convergence (solid) developed along the front at 0100 LST (Fig. 8a), divergence (dashed) existed on both sides of the line. As the line extended in length through 0300 LST, individual convergence centers of $1-2 \times 10^{-3} \mathrm{~s}^{-1}$ embedded in the line also developed about $20-35 \mathrm{~km}$ apart (Fig. 8b). These centers were associated with convective cells, which mostly moved southeastward relative to the line after formation (to be discussed shortly). During this period, northward deflection of the southwesterly flow upstream from the terrain was clear at $687 \mathrm{~m}$. Convergence along the arc-shaped zone also grew south of $24.7^{\circ} \mathrm{N}$ at 0400 LST (Fig. 8c), and increased divergence centers appeared among the convergence ones. Clearly, the arc-shaped convergence zone was ahead of the front, and reached central Taiwan near 0600 LST (Fig. 8d).

Figure 9 presents the distribution of largest total mixing ratio of rain and graupel $\left(\mathrm{g} \mathrm{kg}^{-1}\right)$ in the air column so that it is analogous to Fig. 4 and depicts convective cells, while horizontal winds at $1006 \mathrm{~m}$ (level 7) are also shown. By 0100 LST 23 May, convection had started to develop along the low-level convergence zone at the leading edge of the front (Fig. 9a). During the next 2-3 $\mathrm{h}$, individual cells, some only about $15 \mathrm{~km}$ apart, intensified within the line (Figs. 9b-d). A similar multicell structure was also observed in several TAMEX squall lines or simulated by models (e.g., Wang et al. 1990; Lin et al. 1992; Trier and Parsons 1995). These cells, most

FIG. 7. Simulated horizontal wind $\left(\mathrm{m} \mathrm{s}^{-1}\right)$ and relative vorticity $\left(10^{-4} \mathrm{~s}^{-1}\right)$ at $378 \mathrm{~m}$ in FTRN run at 1-h intervals from (a) 0000 to (h) 0700 LST 23 May 2002. For winds, full (half) barbs represent $10(5) \mathrm{m} \mathrm{s}^{-1}$. Relative vorticity is analyzed at intervals of $5 \times 10^{-4} \mathrm{~s}^{-1}$ plus two additional levels at $\pm 2 \times 10^{-4} \mathrm{~s}^{-1}$ (with dashed for negative values and the zero line omitted), and areas $\geq 1 \times 10^{-3} \mathrm{~s}^{-1}$ or $\leq-1 \times 10^{-3} \mathrm{~s}^{-1}$ are shaded. Thick gray dashed lines indicate the front at $378 \mathrm{~m}$, and sections may be omitted if overlaid with zones of large positive vorticity. The $378-\mathrm{m}$ contour is also plotted. 


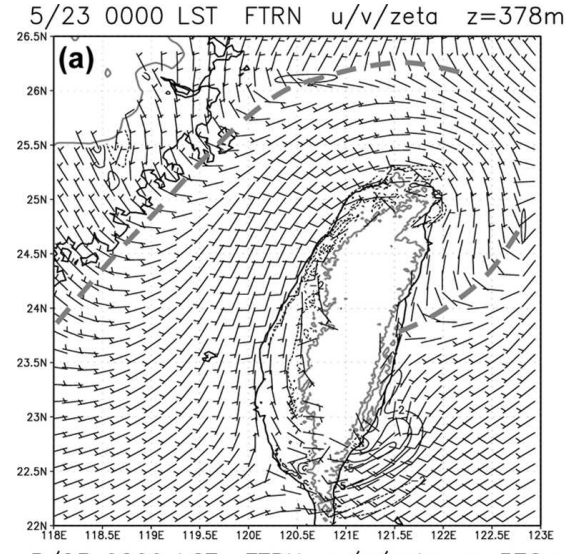

5/230100 LST FTRN u/v/zeta $z=378 m$
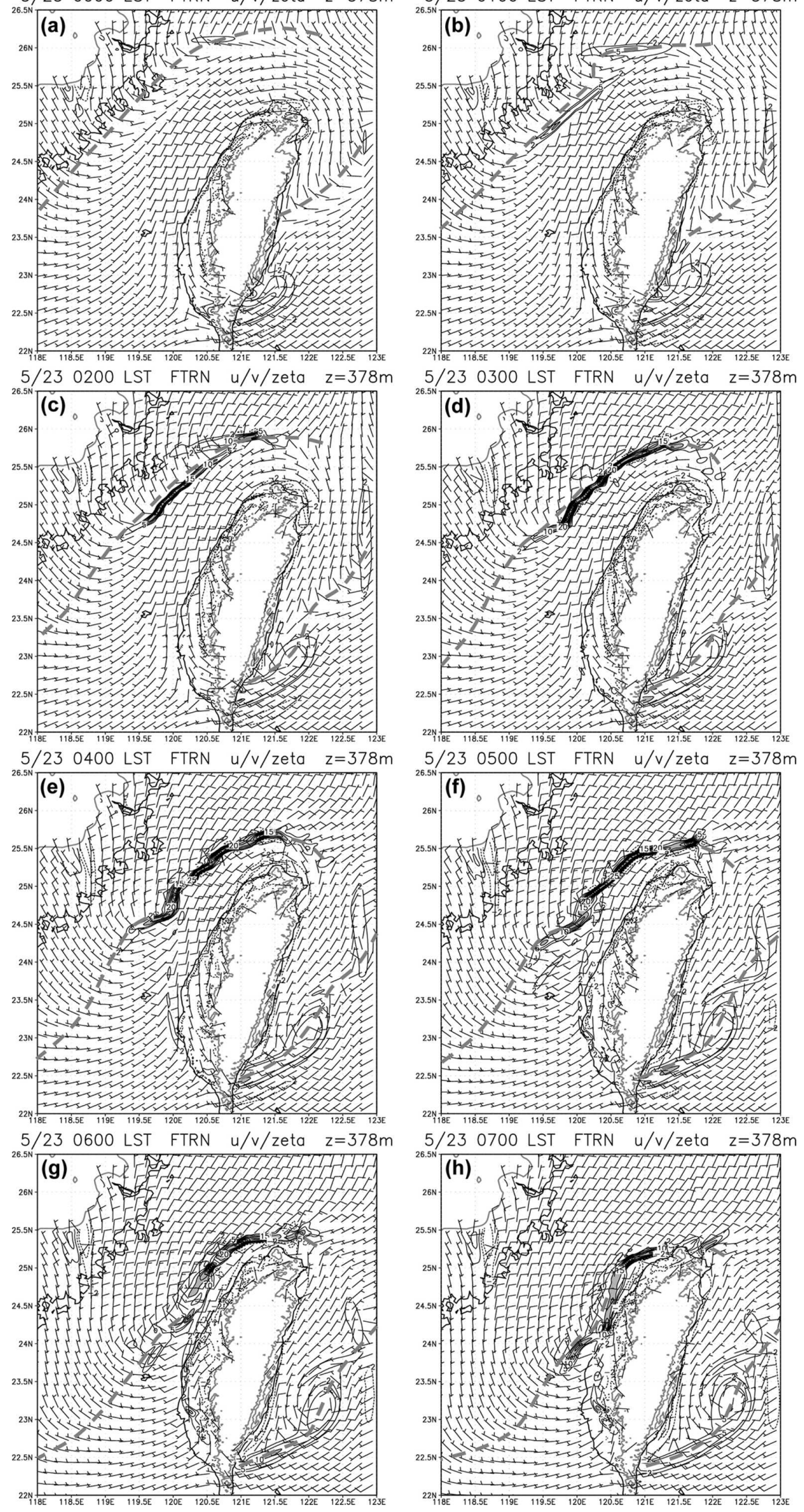
$5 / 230100$ LST FTRN strm/conv $z=687 m$

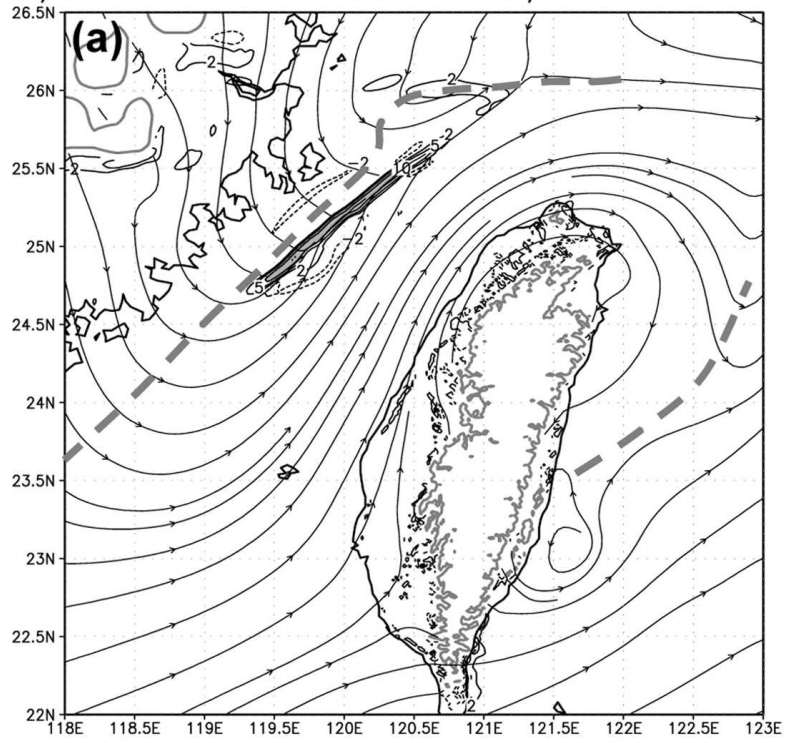

$5 / 230400$ LST FTRN strm/conv $z=687 \mathrm{~m}$

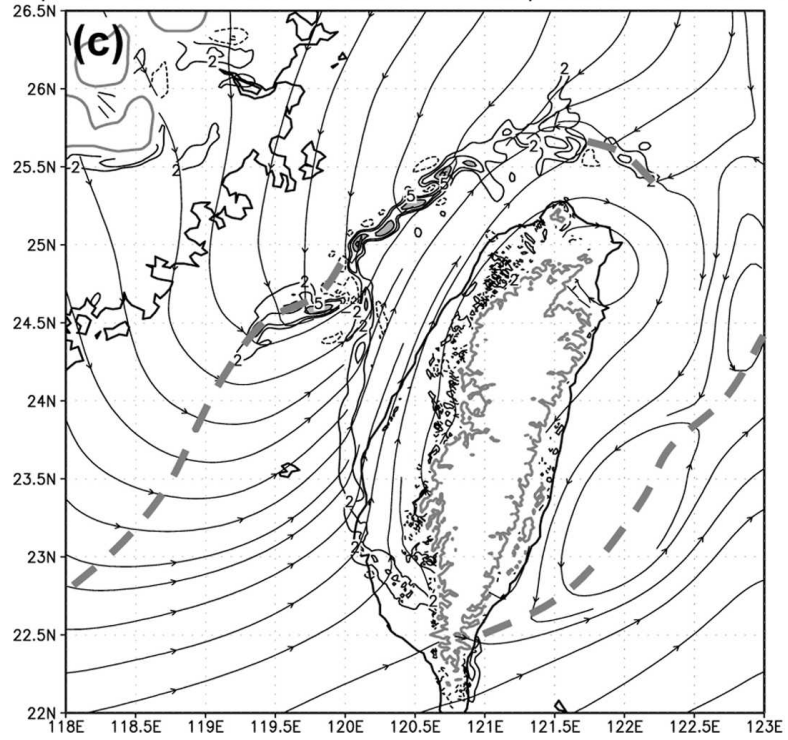

$5 / 230300$ LST FTRN strm/conv $z=687 \mathrm{~m}$

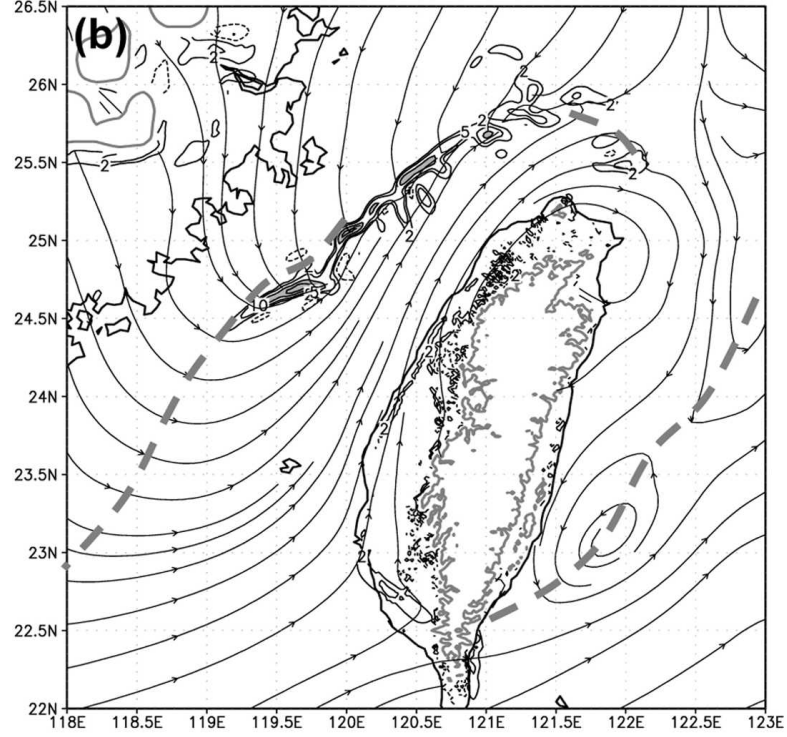

5/230600 LST FTRN strm/conv $z=687 \mathrm{~m}$

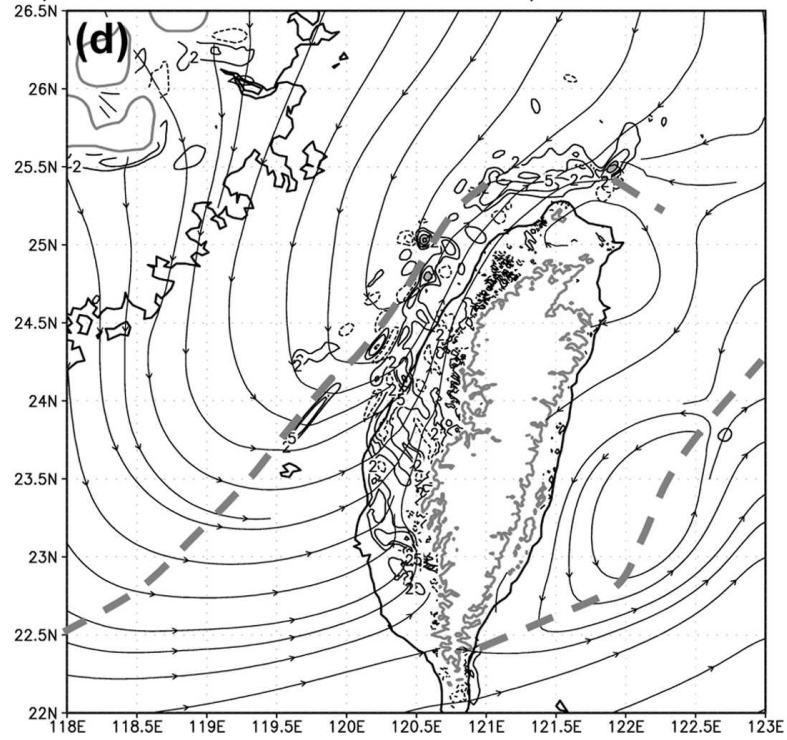

FIG. 8. Same as in Fig. 7, except for streamlines and convergence $\left(10^{-4} \mathrm{~s}^{-1}\right)$ at $687 \mathrm{~m}$ at (a) 0100, (b) 0300, (c) 0400, and (d) $0600 \mathrm{LST}$ 23 May 2002. Isolines and shading values for convergence are the same as those for $\zeta$ in Fig. 7. Fronts at $378 \mathrm{~m}$ and the $687-\mathrm{m}$ contour are also plotted.

lasting for about $2-3 \mathrm{~h}$, were associated with low-level convergence, while divergence often appeared between them or at their immediate backside (cf. Fig. 8). Individual cells propagated toward the general direction of east-southeast after formation, gradually away from the front (collocated with the low-level convergence zone) where new convection was initiated. Although cells in Figs. 4 and 9 did not have an exact one-to-one correspondence, the overall distribution and morphology of simulated cells agreed very well with radar observation.
The southwestern part of the line was generally stronger, similar to the convergence field, where larger and more intense cells tended to form [e.g., the one near $24.7^{\circ} \mathrm{N}, 119.9^{\circ} \mathrm{E}$ at $0300 \mathrm{LST}\left(>6 \mathrm{~g} \mathrm{~kg}^{-1}\right.$; Fig. 9c)]. The cells continued to evolve along the front through 0500 LST (Fig. 9e), and the arc-shaped convergence line also led to the development of a series of about 8-10 isolated cells located off the coast of central to southwestern Taiwan. In fact, the southern end of this arc-shaped line started to develop as early as 0330 LST near 
$5 / 230100$ LST FTRN u/v/q2max z=1006m

$5 / 230200$ LST FTRN u/v/q2max z=1006m
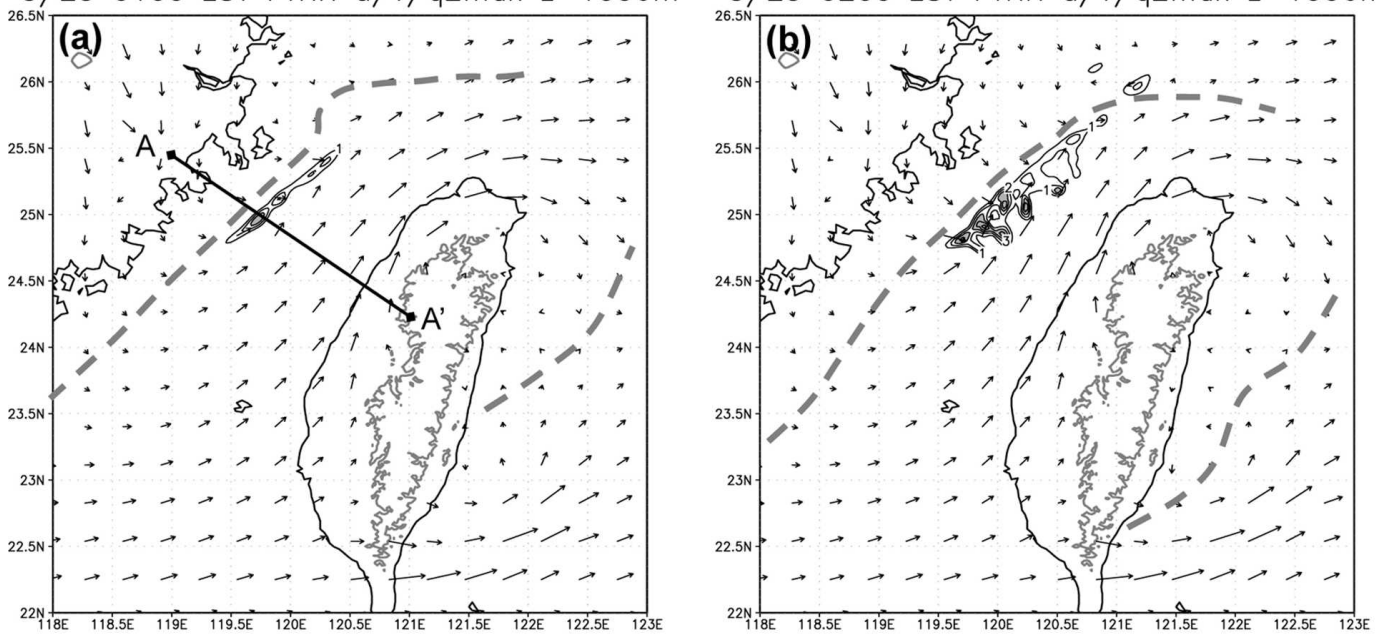

$5 / 230300$ LST FTRN u/v/q2max z=1006m

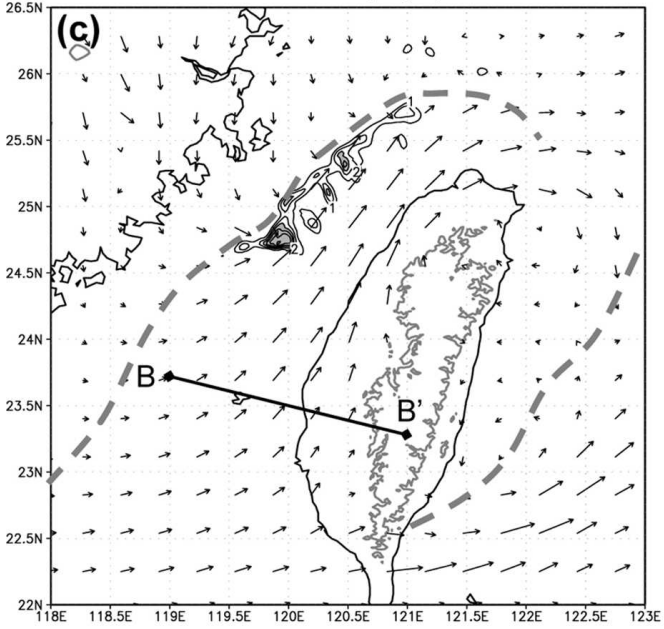

$5 / 230400$ LST FTRN u/v/q2max z=1006m

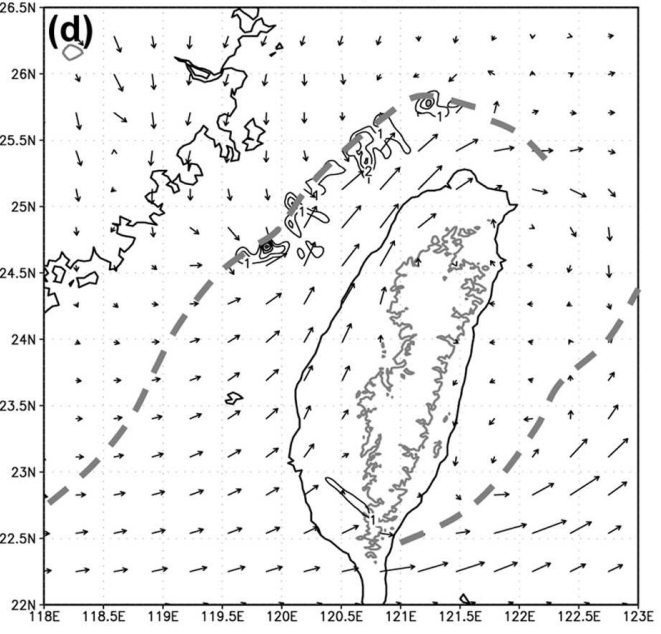

$5 / 230500$ LST FTRN u/v/q2max z=1006m

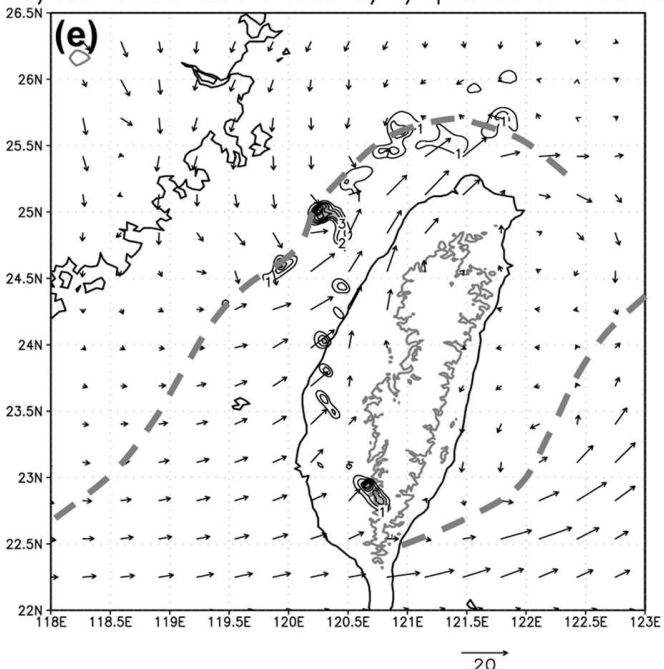

$5 / 230600$ LST FTRN u/v/q2max z=1006m

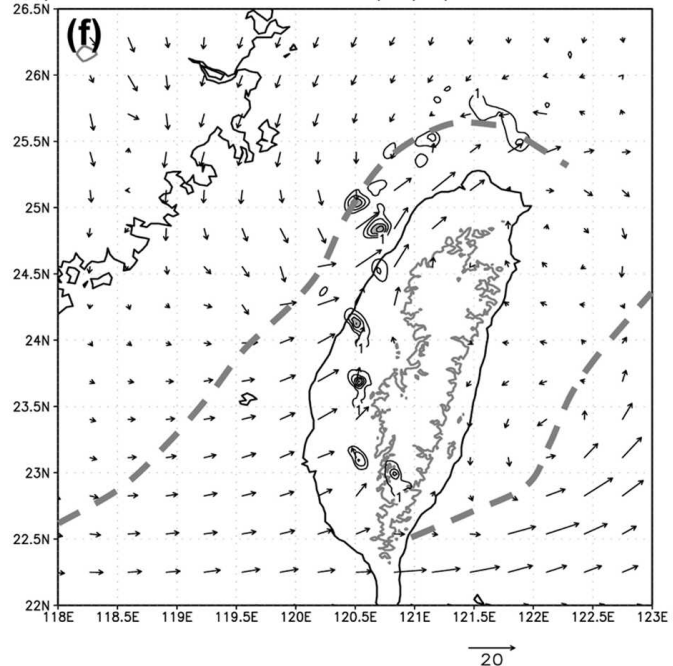

FIG. 9. Same as in Fig. 7, except for simulated maximum mixing ratio $\left(\mathrm{g} \mathrm{kg}^{-1}\right)$ of rain plus graupel in the air column, and horizontal wind vectors at $1006 \mathrm{~m}$ from (a) 0100 to (f) 0600 LST 23 May 2002. The vector length of $20 \mathrm{~m} \mathrm{~s}^{-1}$ is indicated at bottom of (e) and (f). Mixing ratio is analyzed at $1 \mathrm{~g} \mathrm{~kg}^{-1}$ intervals and areas $\geq 3 \mathrm{~g} \mathrm{~kg}^{-1}$ are shaded. Fronts at $378 \mathrm{~m}$ and the 1006-m contour are also plotted. 
$22.8^{\circ} \mathrm{N}, 120.5^{\circ} \mathrm{E}$ (not shown), which is in excellent agreement with observations (Figs. 4c,d; 8b,c; 9d). Afterward, the the cells moved onshore in the prefrontal environment (Figs. 9e,f).

The simulated total rainfall during 0000-1000 LST (Fig. 10) reached a maximum of $140 \mathrm{~mm}$ ahead of the front over the strait (near $25^{\circ} \mathrm{N}, 120.4^{\circ} \mathrm{E}$ ). The rain over land was distributed primarily in the western half of the island with local centers over central and southern Taiwan, showing a pattern in good overall agreement with Fig. 5. The maximum near $24.1^{\circ} \mathrm{N}, 120.8^{\circ} \mathrm{E}$, caused by convection that developed along the arc-shaped convergence zone (cf. Figs. 8 and 9), was close to the observation in location but the value of about $65 \mathrm{~mm}$ was somewhat too small. To the south, the rain was increasingly overpredicted and displaced inland. For instance, the center near $23.2^{\circ} \mathrm{N}, 120.7^{\circ} \mathrm{E}(130 \mathrm{~mm})$ was too large and too far east by about $50 \mathrm{~km}$. This discrepancy was apparently caused by delayed development of cells, and was possibly related to inadequate upstream spacing from the model lateral boundary (less than the estimated $L_{R}$ in section 1) since it occurred closer to the domain edge. The model also produced considerable rainfall along the northwestern coast, as well as a local center of $40 \mathrm{~mm}$ over northern Taiwan (at $25.2^{\circ} \mathrm{N}$, $121.6^{\circ} \mathrm{E}$ ) but the areal extent was too small. Overall, the control run of FTRN experiment was both realistic and contained many fine details. It generally agreed with the observations in the evolution of the mei-yu front, the secondary arc-shaped convergence line, as well as in the resultant weather including the development, morphology, and structure of convection and the associated rainfall distribution.

From the results of the FTRN run, vertical cross sections from $25.4^{\circ} \mathrm{N}, 119^{\circ} \mathrm{E}$ to $24.3^{\circ} \mathrm{N}, 121^{\circ} \mathrm{E}$ (along $\mathrm{AA}^{\prime}$ in Fig. 9a) were constructed to examine the flow and thermodynamic structure in the lower troposphere off the northwestern coast of Taiwan (Fig. 11). As the meiyu front (position as in Fig. 7) moved to about $119.3^{\circ} \mathrm{E}$ at 0000 LST 23 May, prefrontal southwesterly flow was strongest $\left(>10 \mathrm{~m} \mathrm{~s}^{-1}\right)$ just northwest of Taiwan topography (Fig. 11a). The vorticity on its cyclonic shear side over the strait (near $119.4^{\circ}-119.8^{\circ} \mathrm{E}$ ) was still separated from that associated with the front. At this time, deep convection had not formed but there was stratiform cloud below $4 \mathrm{~km}$ over the strait (not shown). At 0200 LST (Fig. 11b), the front moved to about $119.7^{\circ} \mathrm{E}$ with deep convection at its leading edge. Their associated vorticity nearly merged although the convectively induced $\zeta$ was one order of magnitude larger $\left(>2 \times 10^{-3}\right.$ $\mathrm{s}^{-1}$ ). The postfrontal northeasterly flow was about $1-1.5 \mathrm{~km}$ in depth, while the prefrontal flow below about $2.5 \mathrm{~km}$ strengthened. The convection reached

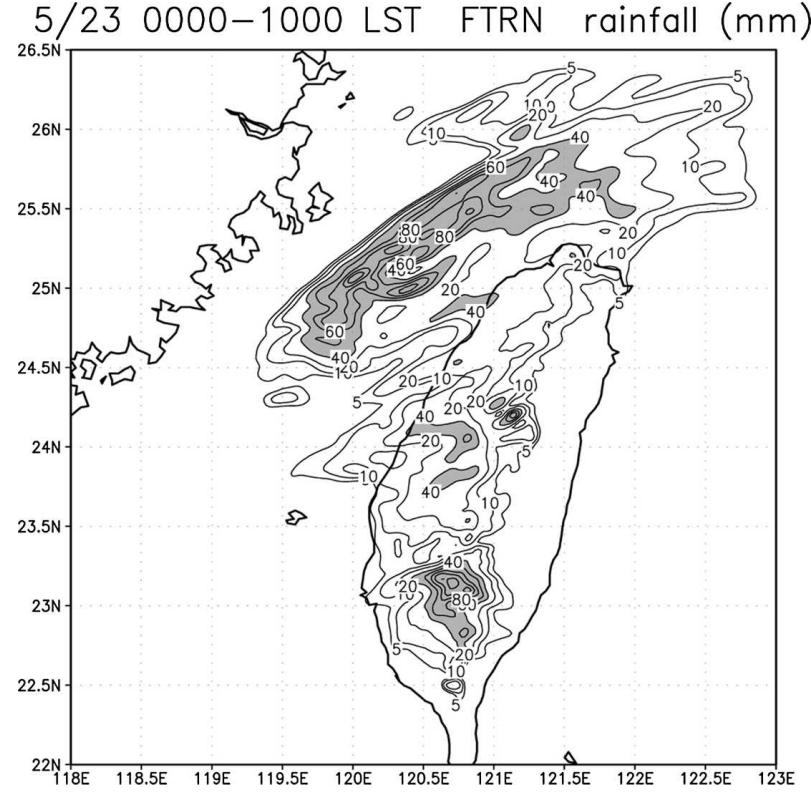

FIG. 10. Same as in Fig. 7, except for simulated 10-h accumulated rainfall $(\mathrm{mm})$ in 0000-1000 LST 23 May 2002. Contour intervals are $20 \mathrm{~mm}$ starting from $20 \mathrm{~mm}$, plus two additional levels at 5 and $10 \mathrm{~mm}$, and areas $\geq 40 \mathrm{~mm}$ are shaded.

about $16 \mathrm{~km}$ (not shown), consistent with Fig. 3, and exhibited a slight forward tilt (Fig. 11b).

The flow structure in the cross section revealed that low-level offshore flow at 0000 UTC extended from the terrain of Taiwan out to about $119.8^{\circ} \mathrm{N}$, where convergence of $1-2 \times 10^{-4} \mathrm{~s}^{-1}$ existed below $1 \mathrm{~km}$ near the surface (Fig. 11c). As the prefrontal flow strengthened, offshore flow also increased in speed and depth (to about $1.2-2 \mathrm{~km}$ ) at $0200 \mathrm{LST}$ (Fig. 11d). The convergence accompanying the deep convection reached $1 \times$ $10^{-3} \mathrm{~s}^{-1}$ all the way up to the midtroposphere. Below 6 $\mathrm{km}$, the largest vertical velocity reached almost $5 \mathrm{~m} \mathrm{~s}^{-1}$ at $0200 \mathrm{LST}$, but peak ascent of nearly $13 \mathrm{~m} \mathrm{~s}^{-1}$ occurred at $11 \mathrm{~km}$ (not shown). Ahead of the convergence line, downdrafts also existed with divergence (below 4.5 $\mathrm{km}$ ), but the divergence immediately behind the line was present only within a narrow zone (of about $10 \mathrm{~km}$ in width; Fig. 11d). The distribution of equivalent potential temperature $\left(\theta_{e}\right)$ at 0000 LST indicated potential instability to moist ascent below $4 \mathrm{~km}$, especially over the strait, as well as stronger gradients behind the front (Fig. 11e). The $\theta$ gradient of the front was very weak but stable to dry ascent (not shown), and yielded buoyancy oscillation frequency $(N)$ values of about 1.1-1.3 $\mathrm{s}^{-1}$ below $6 \mathrm{~km}$. In the prefrontal southwesterly flow, RH was high and reached over $95 \%$ even at the surface $\left(119.6^{\circ}-120^{\circ} \mathrm{E}\right)$. It was somewhat lower $(<90 \%)$ at regions where offshore flow existed most likely because the air was originating from drier (and elevated) land 
(a) $5 / 230000$ LST FTRN $\mathrm{vn} / \mathrm{q} 3 /$ zeta CS1

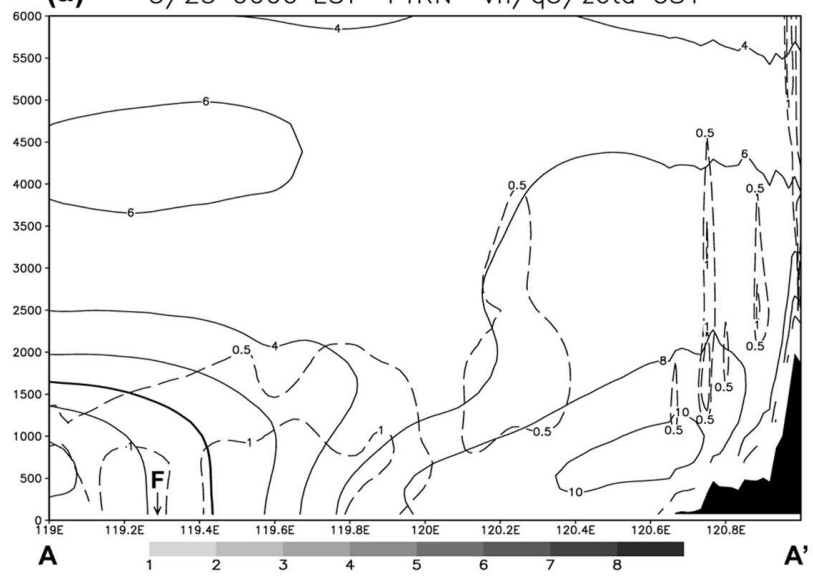

(c)

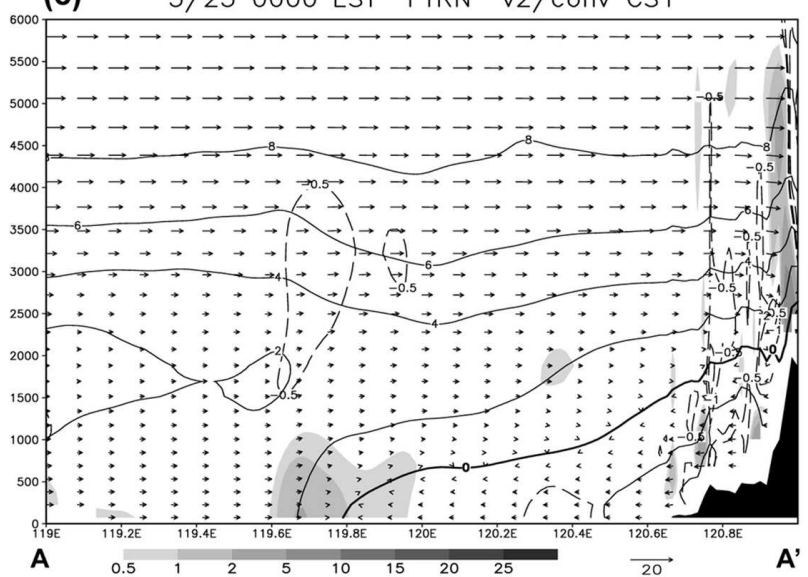

(e)

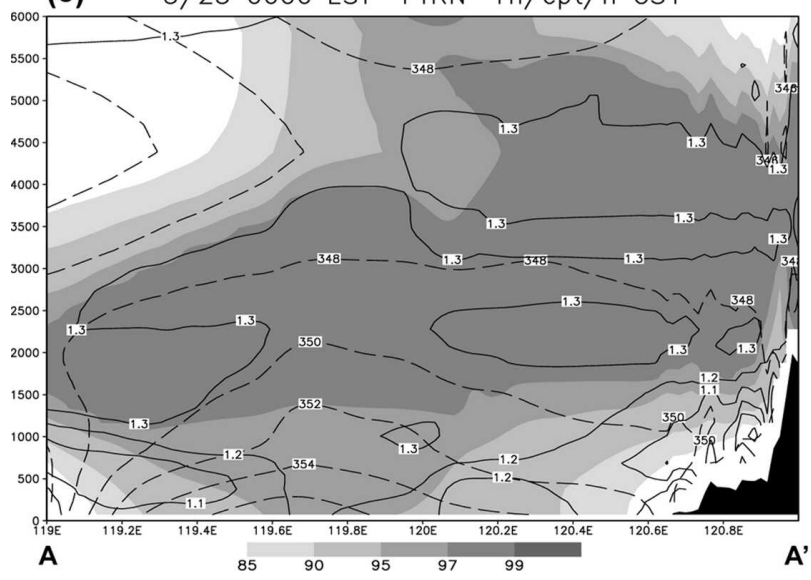

(b) $5 / 230200$ LST FTRN vn/q3/zeta CS 1

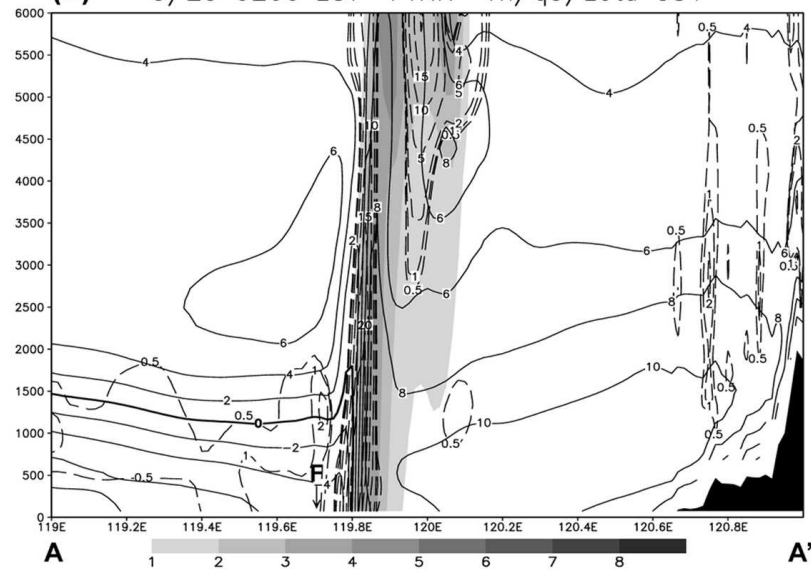

(d)

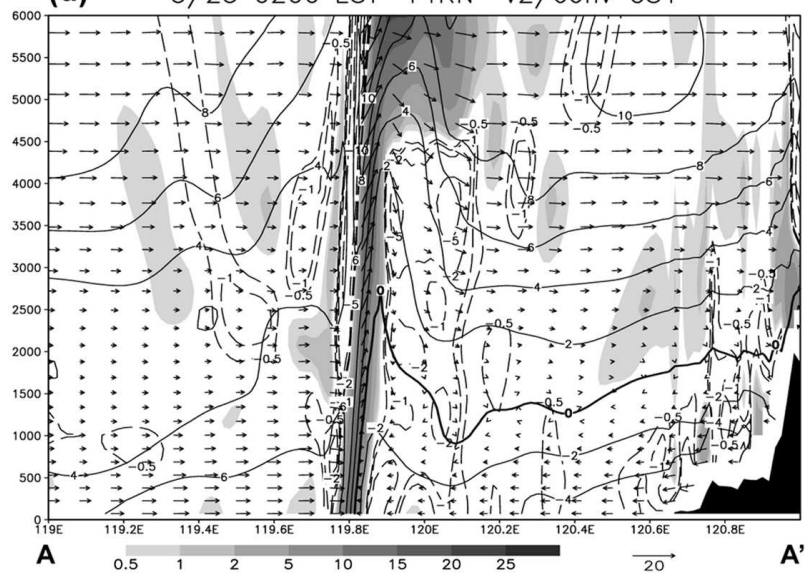

(f)

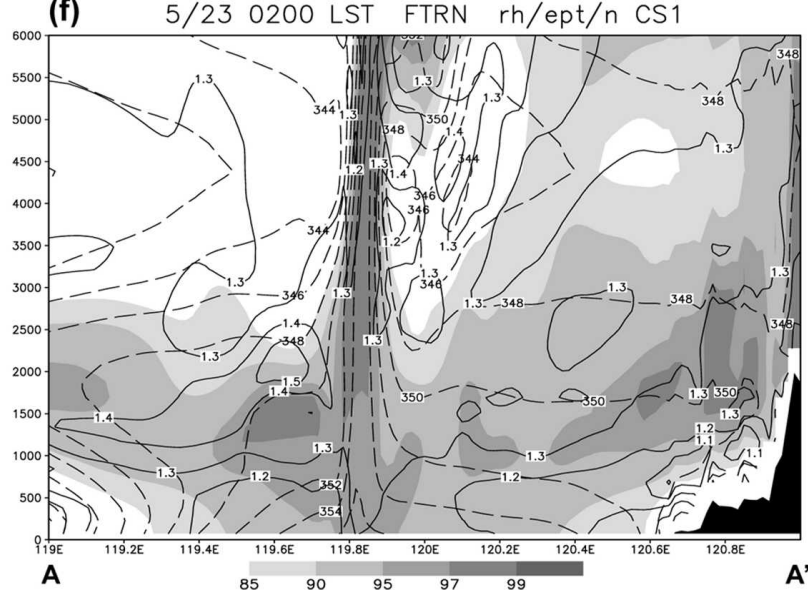

FIG. 11. Vertical cross sections from $25.4^{\circ} \mathrm{N}, 119^{\circ} \mathrm{E}$ to $24.3^{\circ} \mathrm{N}, 121^{\circ} \mathrm{E}$ ( $\mathrm{AA}^{\prime}$ in Fig. 9a) in the lowest $6 \mathrm{~km}$ in the FTRN run at (a), (c), (e) 0000 and (b), (d), (f) 0200 LST 23 May 2002. (a) Total mixing ratio of precipitating hydrometeors $\left(q_{r}+q_{s}+q_{g}, \mathrm{~g} \mathrm{~kg}^{-1}\right.$, shading), speed of horizontal wind normal to cross section $\left(\mathrm{m} \mathrm{s}^{-1}\right.$, solid, positive for into the plane and zero line thickened), and relative vorticity ( $\zeta, 10^{-4} \mathrm{~s}^{-1}$, dashed, positive only). (c) Convergence $\left(10^{-4} \mathrm{~s}^{-1}\right.$, shading for positive and dashed lines for negative values), and $2 \mathrm{D}$ vectors and speed of horizontal wind ( $\mathrm{m} \mathrm{s}^{-1}$, solid, zero line thickened) along the section plane. (e) Relative humidity (\%, shading), buoyancy oscillation frequency $\left(N, 10^{-2} \mathrm{~s}^{-1}\right.$, solid) and equivalent potential temperature $\left(\theta_{e}, \mathrm{~K}\right.$, dashed). (b), (d), (f) Same as (a), (c), (e) except for 0200 LST. Contour intervals are $5 \times 10^{-4} \mathrm{~s}^{-1}$ plus $( \pm) 0.5,1$, and $2 \times 10^{-4} \mathrm{~s}^{-1}$ for $\zeta$ and convergence and $2 \mathrm{~m} \mathrm{~s}{ }^{-1}$ for wind speed (a)-(d), and $2 \mathrm{~K}$ for $\theta_{e}$ and $0.1 \times 10^{-2} \mathrm{~s}^{-1}$ for $N$ (e), (f). The letter "F" marks the position of the front in (a), (b). A vertical distance of $1 \mathrm{~km}$ represents $10 \mathrm{~m} \mathrm{~s}^{-1}$ in (c), (d). 


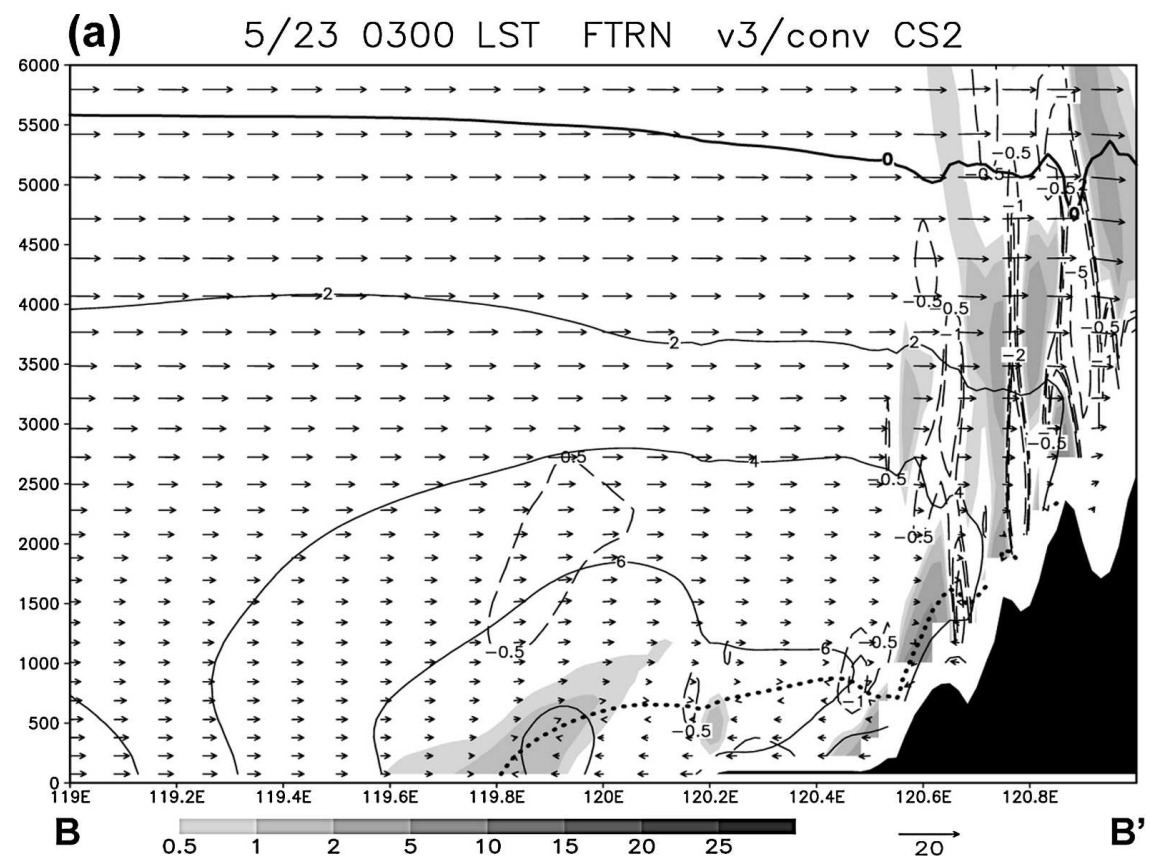

(b) $5 / 230300$ LST FTRN rh/ept/n CS2

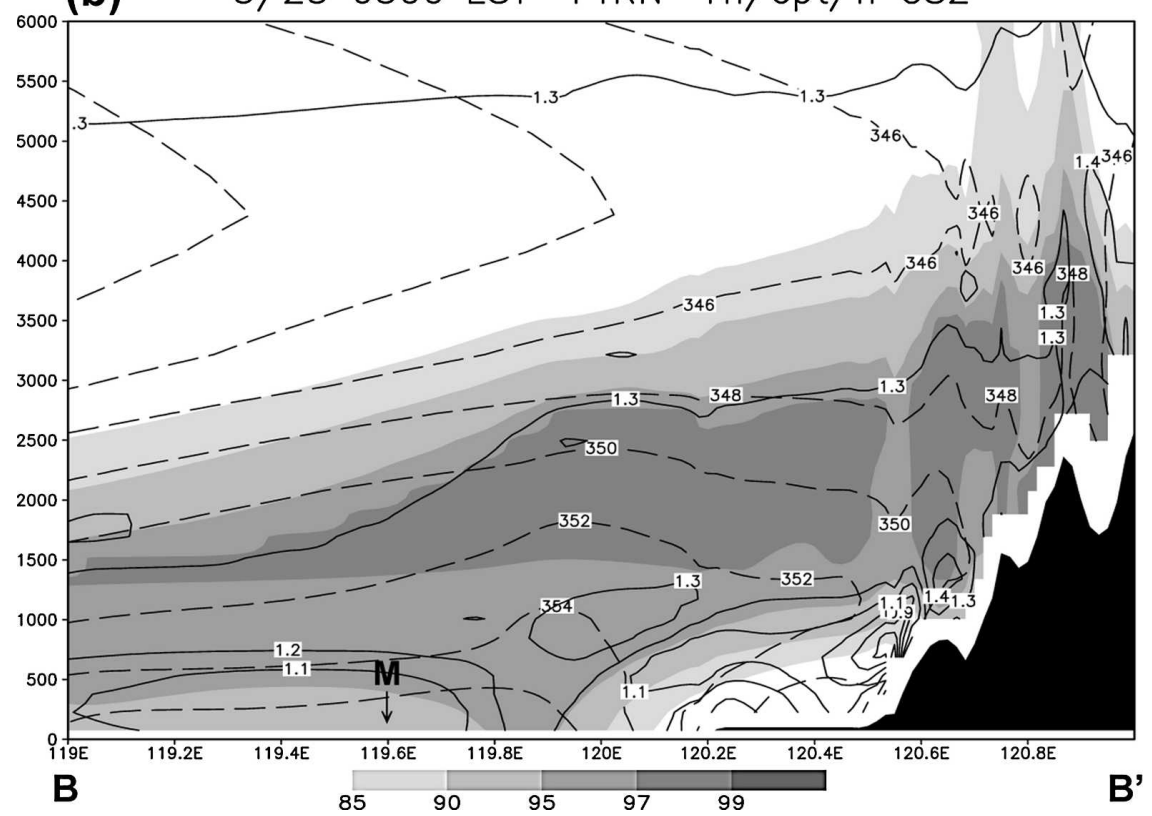

Fig. 12. Vertical cross sections from $23.7^{\circ} \mathrm{N}, 119^{\circ} \mathrm{E}$ to $23.3^{\circ} \mathrm{N}, 121^{\circ} \mathrm{E}$ (BB' in Fig. $9 \mathrm{c}$ ) in the lowest $6 \mathrm{~km}$ in the FTRN run at 0300 LST 23 May 2002. (a) Convergence $\left(10^{-4} \mathrm{~s}^{-1}\right.$, shading for positive and dashed lines for negative values), speed of horizontal wind normal to the section plane $\left(\mathrm{m} \mathrm{s}^{-1}\right.$, solid), and $2 \mathrm{D}$ wind vectors $\left(\mathrm{m} \mathrm{s}^{-1}\right)$ along the section plane (with zero horizontal speed depicted by the dotted line). Contour intervals and vector lengths are the same as in Figs. 11a,c. (b) Same as in Fig. 11e, except along BB' at 0300 LST 23 May 2002. The letter "M" marks the location of Makung station.

areas (Figs. 11c,e). Lower RH values also existed near the steep terrain over land, where local $N$ values decreased to below $1.0 \mathrm{~s}^{-1}$. While the convection was associated with high moisture content at 0200 LST,
$\mathrm{RH}$ southeast of the line in the lower troposphere decreased significantly due to subsidence warming from downdrafts and compensational sinking motion (Fig. 11f). 

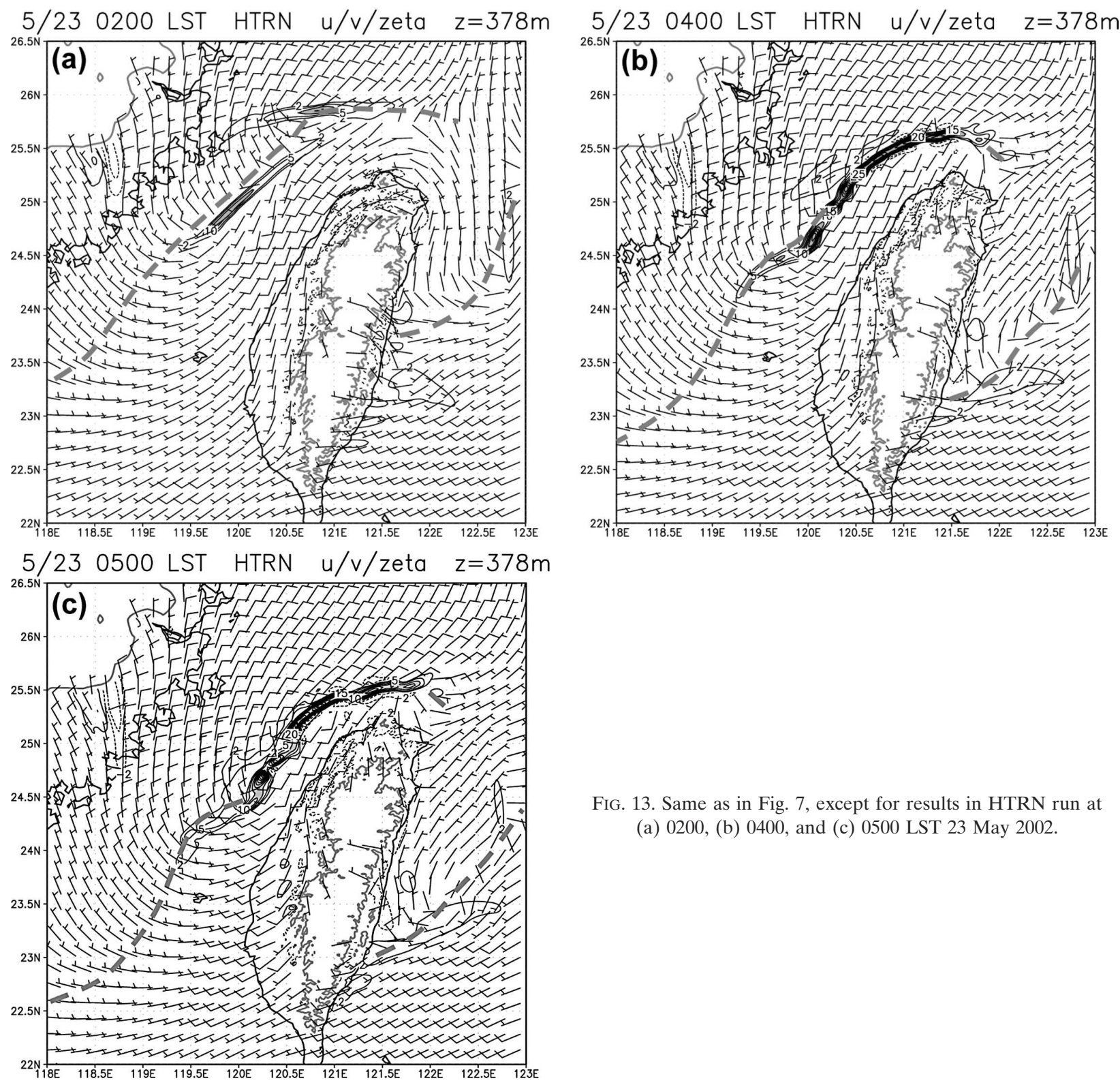

FIG. 13. Same as in Fig. 7, except for results in HTRN run at (a) 0200, (b) 0400, and (c) 0500 LST 23 May 2002.

Along the cross section perpendicular to the terrain of the southern CMR from $23.7^{\circ} \mathrm{N}, 119^{\circ} \mathrm{E}$ to $23.3^{\circ} \mathrm{N}$, $121^{\circ} \mathrm{E}$ (BB'; cf. Fig. 9c), near-surface offshore flow was also seen at 0300 LST below $1 \mathrm{~km}$ with local convergence at its leading edge near $119.8^{\circ} \mathrm{E}$ (Fig. 12a). This is where the arc-shaped convergence line formed in Fig. 8. Consistent with the earlier discussion, the prevailing flow was weaker farther south with a speed of only 8 $\mathrm{m} \mathrm{s}^{-1}$ near $119.9^{\circ} \mathrm{E}$. At the lowest $1 \mathrm{~km}$, the air over land was again not saturated with $N \approx 1.2 \times 10^{-2} \mathrm{~s}^{-1}$ although more moist conditions existed offshore near the arc-shape convergence zone and Makung (marked "M" in Fig. 12b, cf. Fig. 3). Together with a mean $h \approx$
$2.5 \mathrm{~km}$ and $U \approx 7.5 \mathrm{~m} \mathrm{~s}^{-1}$ in the lower troposphere (Fig. 12a), Fr is estimated to be about 0.25 and a blocked flow regime was favored in the FTRN run as the flow was not saturated.

\section{b. The HTRN experiment}

Results of the HTRN run, in which the terrain of Taiwan was reduced by half, are presented in Figs. 1317, and can be directly compared with Figs. 7-10 and 12 . At $378 \mathrm{~m}$, the vorticity started to intensify along the mei-yu front in a similar way as in the FTRN run, but occurred about 30 min later and slightly closer to Taiwan (not shown). During the following hours, the front 

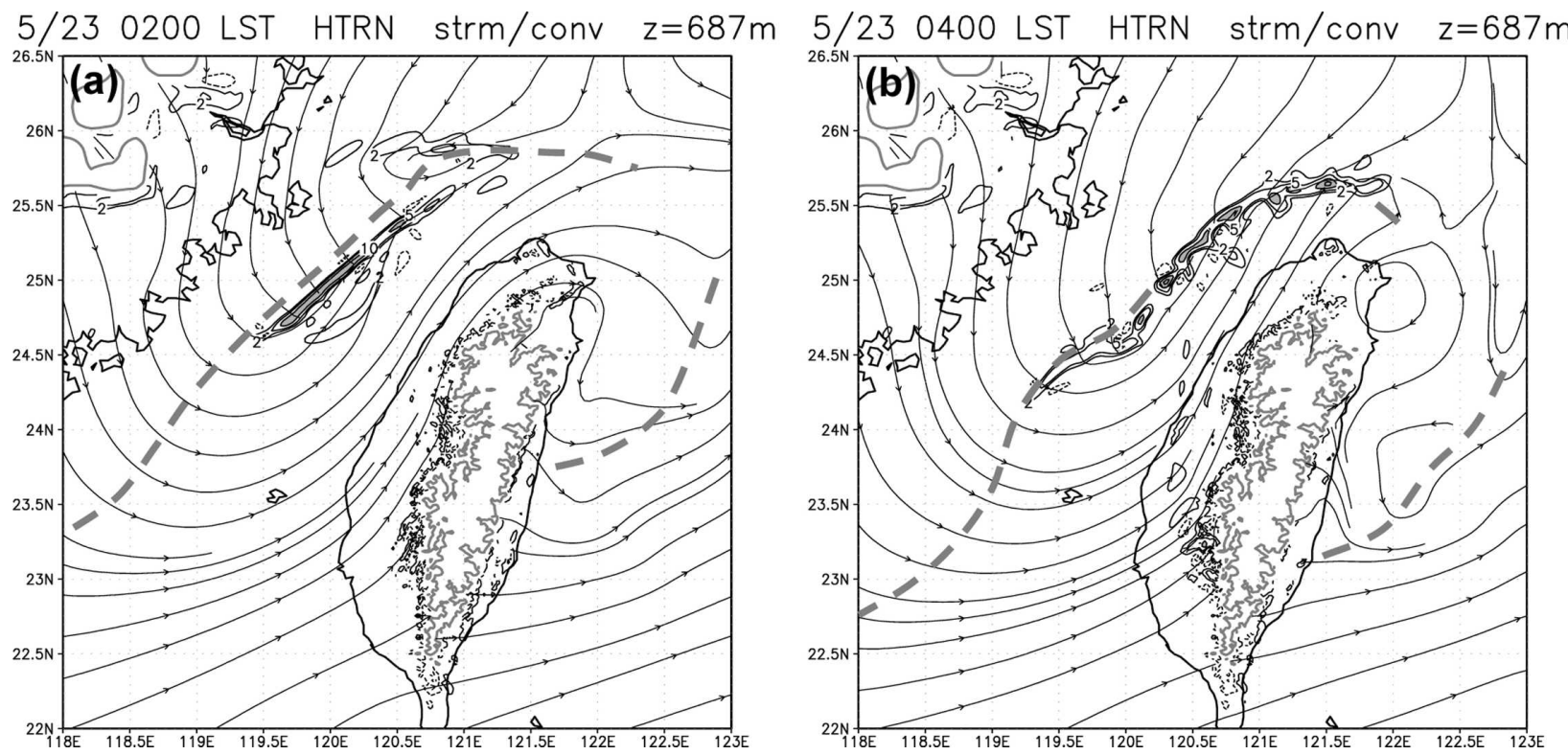

FIG. 14. Same as in Fig. 8, except for results in HTRN run at (a) 0200 and (b) 0400 LST 23 May 2002.

continued to approach Taiwan with individual vorticity centers (Fig. 13a), and its overall shape at 0400 LST resembled that at 0300 LST in the FTRN run (Figs. 13b and $7 \mathrm{~d}$ ). The vorticity center near $24.7^{\circ} \mathrm{N}, 120.2^{\circ} \mathrm{E}$ reached its peak intensity of about $4 \times 10^{-3} \mathrm{~s}^{-1}$ at 0500 LST, and small vorticity centers also appeared over western Taiwan along about $120.5^{\circ} \mathrm{E}$ (Fig. 13c). This second vorticity zone, when compared with the one in the FTRN run, was significantly weaker, shorter in length (evident only at $23^{\circ}-24^{\circ} \mathrm{N}$ ), and displaced eastward by about $50 \mathrm{~km}$. The frontal vorticity zone slowly weakened afterward and reached central Taiwan at 0700 LST with an overall strength similar to that in the FTRN run (not shown). At $378 \mathrm{~m}$, the vortex southeast of Taiwan was also much weaker in the HTRN run (Fig. 13).

The enhancement of convergence at $687 \mathrm{~m}$ in the HTRN run was also delayed by about $30 \mathrm{~min}$ to $1 \mathrm{~h}$ (not shown). At 0200-0400 LST, individual centers grew to about 1-1.5 $\times 10^{-3} \mathrm{~s}^{-1}$ (somewhat weaker than in the FTRN run) as fragmentation of the convergence zone became increasingly severe (Figs. 14a,b). Appearing as a series of isolated centers, the north-south convergence zone was also weaker and formed over the island farther to the east (Figs. 8c and 14b). With the terrain reduced, the northward deflection of the flow west of the CMR was not as clearly visible especially at 0600 LST, suggesting that the air at $687 \mathrm{~m}$ could flow over a lowered mountain (not shown).

Strong convection did not develop until after 0200 LST in the HTRN run (Fig. 15a), and cells over $6 \mathrm{~g} \mathrm{~kg}^{-1}$ appeared at 0300 LST near $24.8^{\circ} \mathrm{N}$ and $120^{\circ} \mathrm{E}$ (not shown). Once the cells propagated ahead of the line, however, they tended to weaken more quickly than in the FTRN run and mostly lasted shorter than $3 \mathrm{~h}$. Hence, few cells with appreciable strength reached the coastline of Taiwan by 0500 LST (Figs. 15b,c). From 0500 LST onward, strong convection over southern Taiwan also started to develop then moved across (a reduced) CMR (Figs. 15c,d). Since these cells also appeared in the NTRN run (to be described), they were most likely not triggered by mechanical uplift of lowlevel flow over the terrain, but their evolution was certainly impacted by orographic effects. The 10-h total rainfall simulated in the HTRN run (Fig. 16) was concentrated along and ahead of the front and was closer to Taiwan than in the FTRN run (cf. Fig. 10). As expected, the rainfall over land was mainly over the CMR rather than along the coastal regions in central Taiwan. The maximum center of $80 \mathrm{~mm}$ over northern Taiwan $\left(25^{\circ} \mathrm{N}, 121.4^{\circ} \mathrm{E}\right)$ was produced after $0700 \mathrm{LST}$ when the front made landfall (cf. Fig. 15). Thus, model rainfall patterns were clearly quite sensitive to the height of the terrain, concentrating near the coast in the FTRN run but more inland over the mountains in the HTRN experiment.

In the HTRN run, offshore flow at 0300 LST was weaker and shallower (limited to the lowest 500-700 $\mathrm{m}$ ), with convergence around $120.2^{\circ} \mathrm{E}$ on the same cross section of $\mathrm{BB}^{\prime}$ (Fig. 17). With everything else being equal, a reduction of terrain height by half gives a doubled value of 0.5 for Fr. Consistent with theoretical 
5/230200 LST HTRN u/v/q2max z=1006m

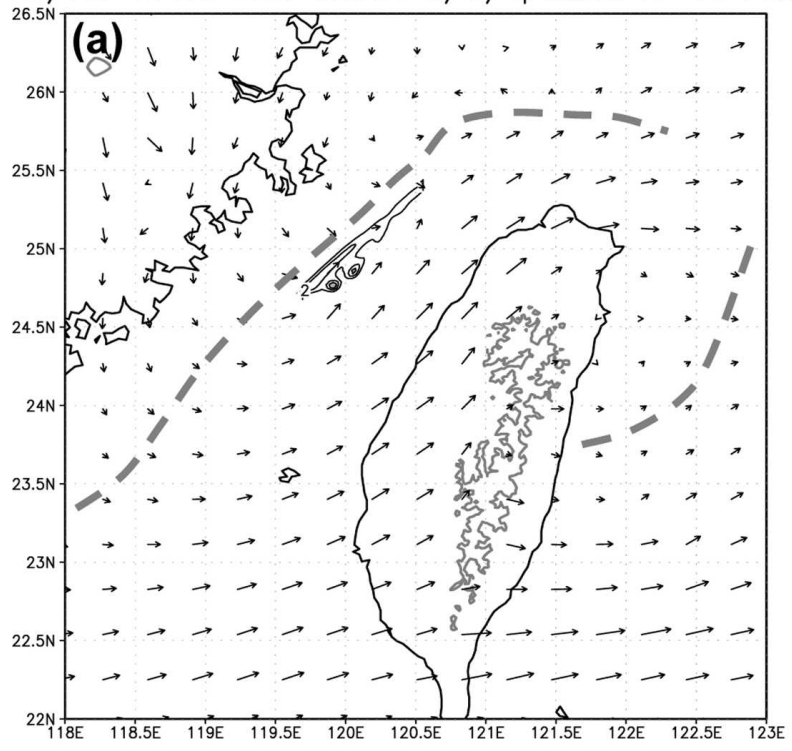

$5 / 230500$ LST HTRN u/v/q2 max $z=1006 m$

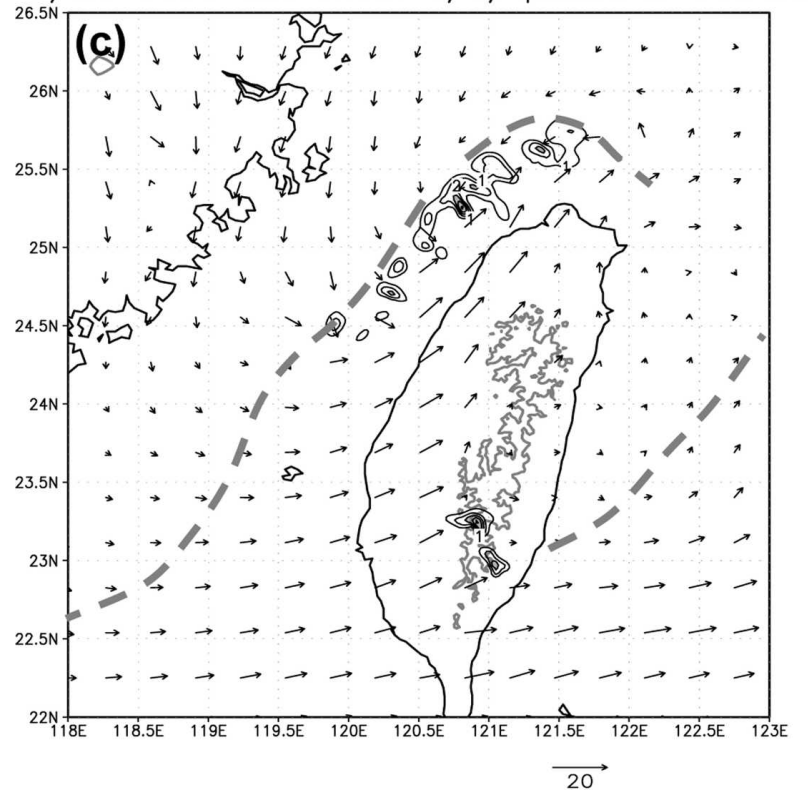

5/23 0400 LST HTRN u/v/q2max z=1006m

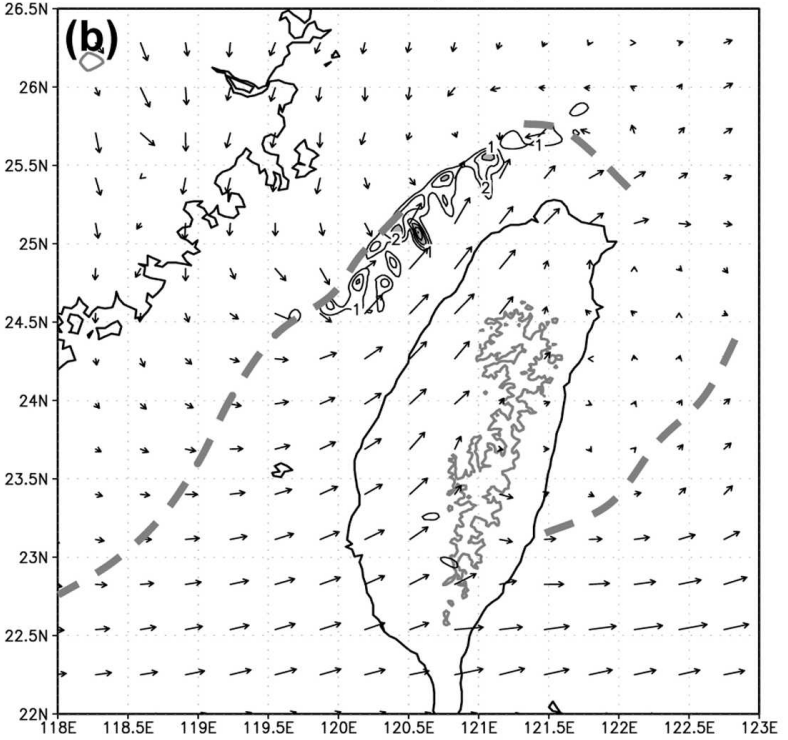

5/230600 LST HTRN u/v/q2max z=1006m

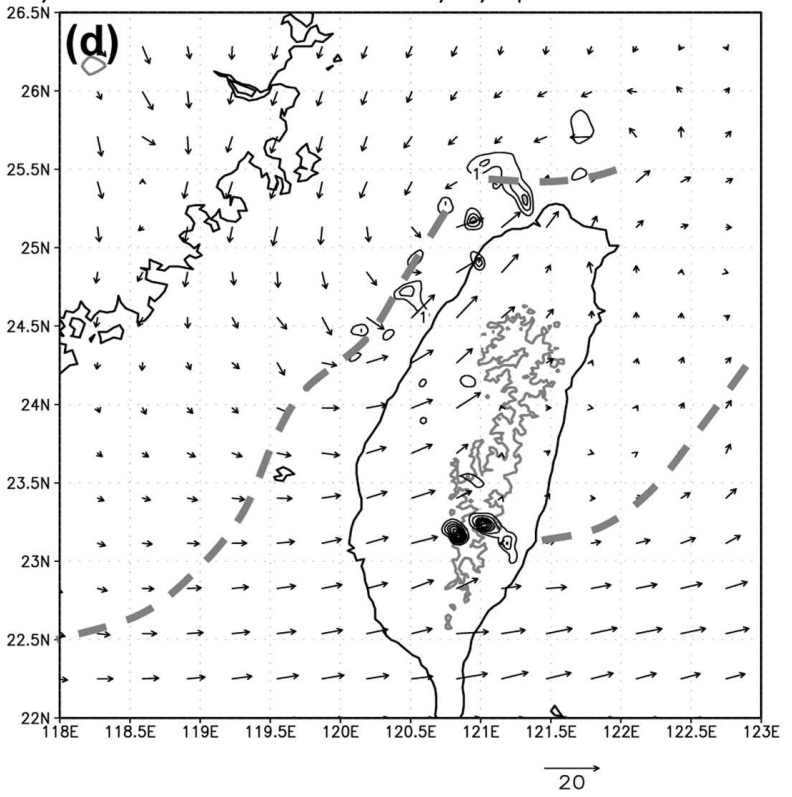

FIG. 15. Same as in Fig. 9, except for results in HTRN run at (a) 0200, (b) 0400, (c) 0500, and (d) 0600 LST 23 May 2002.

expectations, blocking still occurred but the thickness of the blocked flow was reduced and air parcels above 0.7-1 km could flow over the terrain (Figs. 14, 15, and 17). When the terrain height was reduced and Fr increased, the displacement of rainfall farther inland in the HTRN run also agreed with results from the two MAP cases (e.g., Rotunno and Ferretti 2003; Medina and Houze 2003) described in section 1. However, unlike the MAP cases, the total rainfall amount was similar in the FTRN and HTRN runs (Figs. 10 and 16) since the basic speed and stability of low-level flow were the same.

\section{c. The NTRN experiment}

In the NTRN run, the two vorticity zones aligned east-west and northeast-southwest developed even slower than in the HTRN run (not shown). After the two zones merged near 0300 LST (Fig. 18a), individual vorticity centers grew along the front to reach peak intensity at $0500 \mathrm{LST}$ (Fig. 18b). The center at $24.6^{\circ} \mathrm{N}$ 


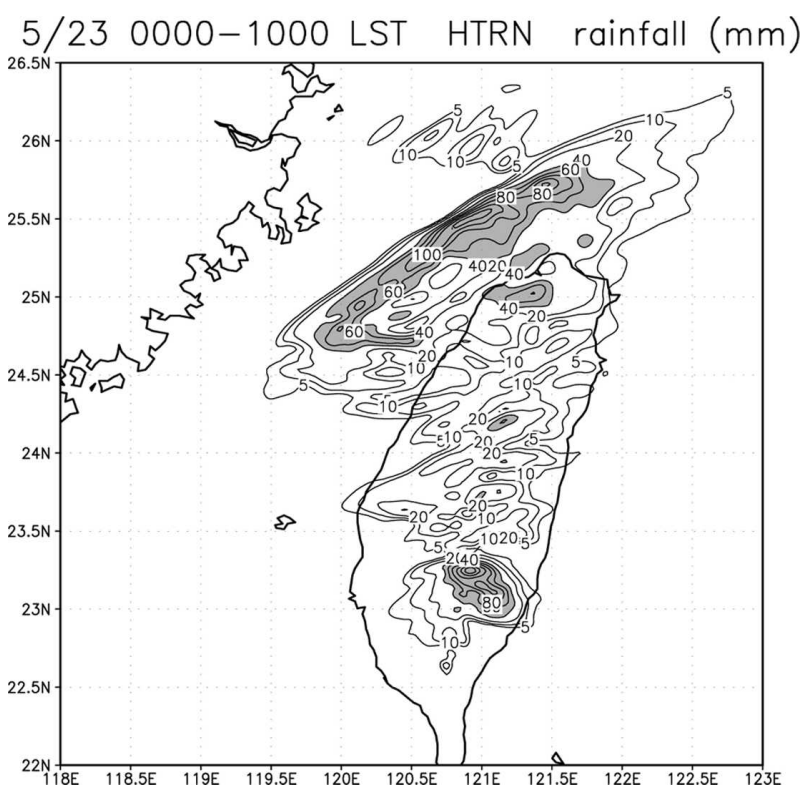

FIG. 16. Same as in Fig. 10, except for results in HTRN run.

and $120.2^{\circ} \mathrm{E}$ exceeded $3 \times 10^{-3} \mathrm{~s}^{-1}$ and the line north of $25^{\circ} \mathrm{N}$ was mostly above $2 \times 10^{-3} \mathrm{~s}^{-1}$. These values were smaller than those obtained in both FTRN and HTRN runs, and indicated a less intense front without the terrain. On the other hand, the shape of the frontal vorticity showed less distortion, and the front traveled slightly faster as it moved close to northern Taiwan after 0600 LST in the NTRN run (not shown), consistent with Braun et al. (1997) and Neiman et al. (2004). As expected, the vortex southeast of Taiwan did not form in the NTRN run (cf. Fig. 2), suggesting that its formation was indeed due to terrain blocking.

A weak low-level convergence zone also formed in the NTRN run even when the flow was not blocked in any way (not shown). As the convergence at $687 \mathrm{~m}$ reached maximum strength at 0430-0500 LST, only a few isolated centers reached $1.5 \times 10^{-3} \mathrm{~s}^{-1}$ (Fig. 19). The individual centers over central and southern Taiwan at 0500 LST, in their subsequent development, exhibited a northeast-southwest orientation (not shown) and aligned differently from the arc-shaped convergence zone (roughly parallel to the terrain) in FTRN and HTRN runs. These centers evolved in regions of wind speed convergence (cf. Fig. 18) and did not appear until later and farther east in the NLND run (not shown). Cross-section analysis indicated that they were triggered near the land-sea boundary by the weak convergence due to differential friction (not shown).

The appearance of more active convection in the NTRN run was not until 0300 LST, also later by comparison (Fig. 20a). Stronger cells tended to form only south of $25.2^{\circ} \mathrm{N}$ in the subsequent development, and the northern section of the front was significantly less active without Taiwan topography (Figs. 20b,c). Again, these cells weakened before they could reach the northwestern coast of Taiwan. Nevertheless, deep convection

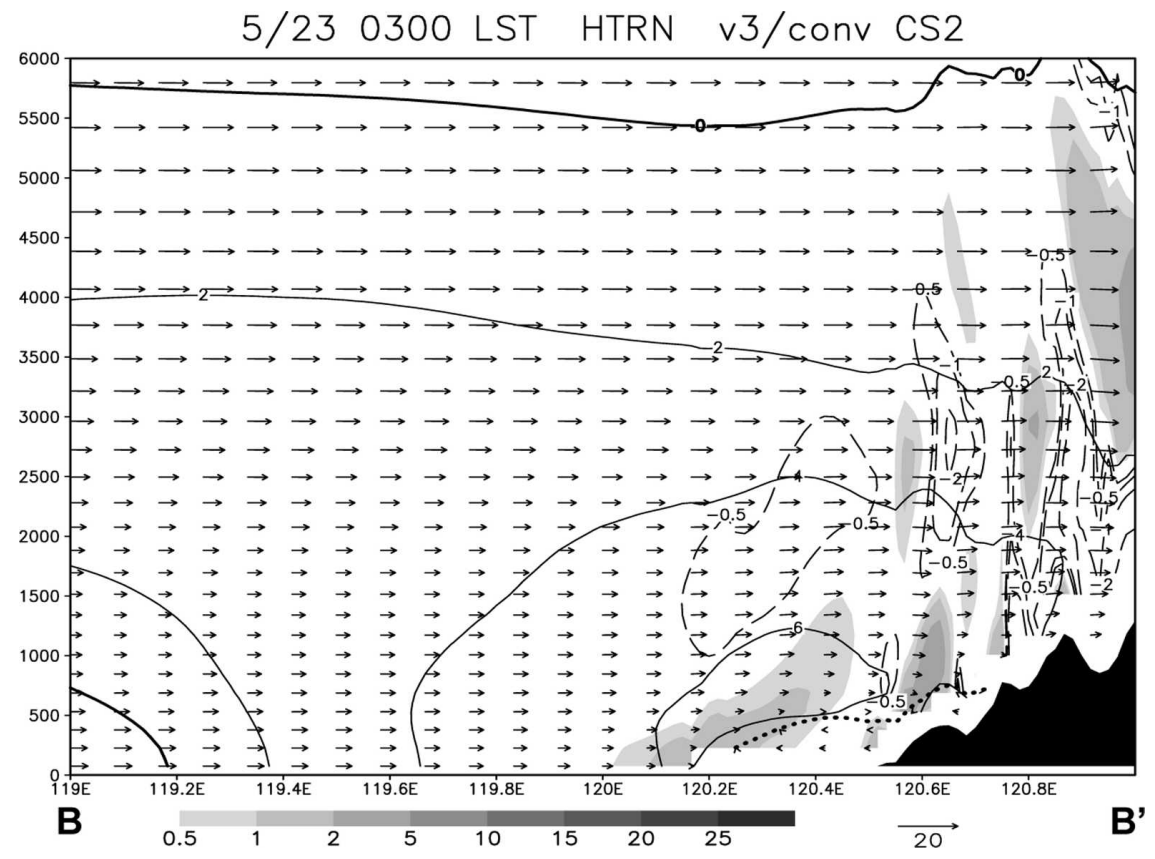

FIG. 17. Same as in Fig. 12a, except for results in the HTRN run. 

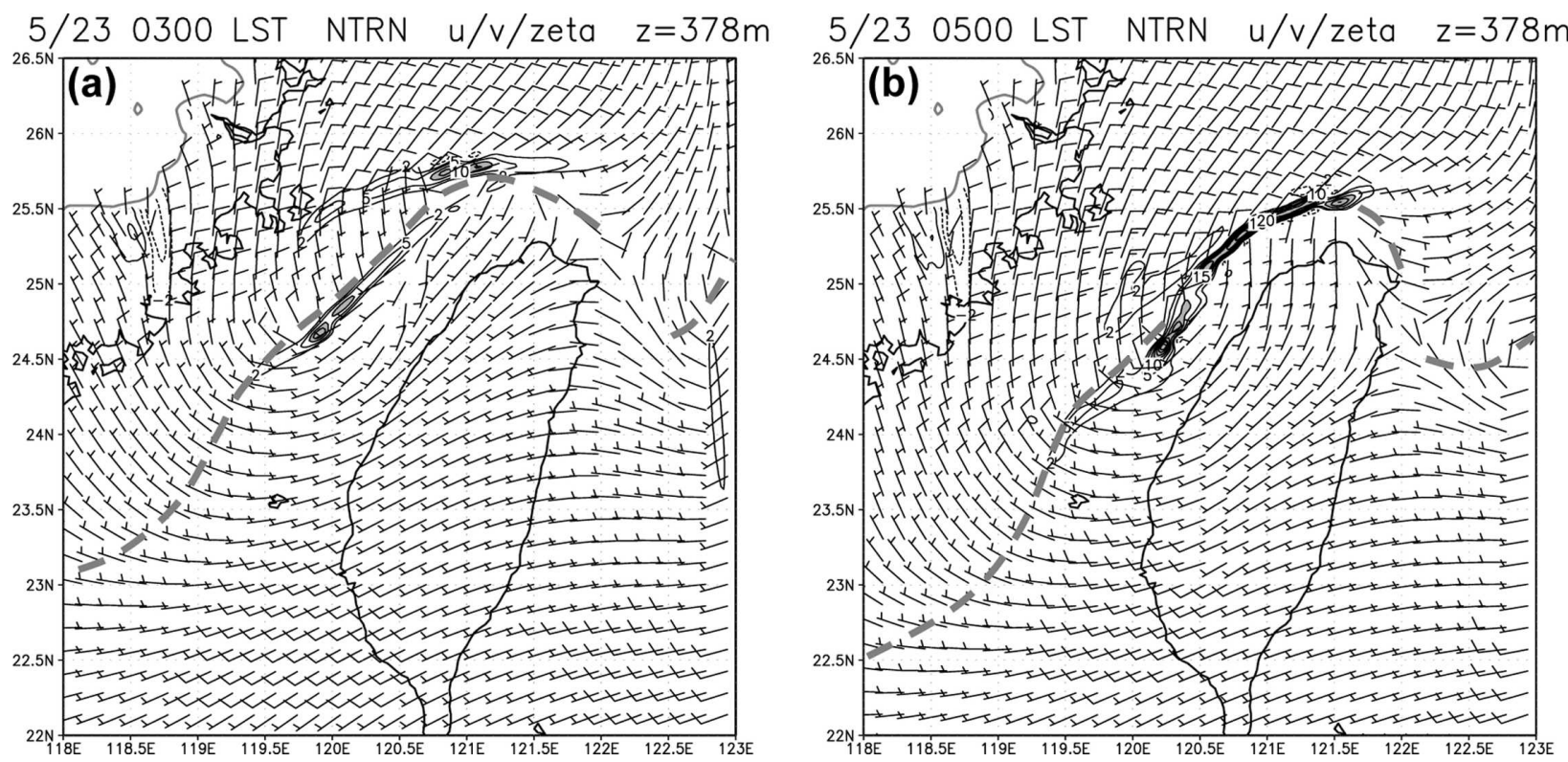

FIG. 18. Same as in Fig. 7, except for results in NTRN run at (a) 0300 and (b) 0500 LST 23 May 2002.

still broke out over southern Taiwan by 0600 LST near $121^{\circ} \mathrm{E}$ (Fig. 20d), farther east than in experiments with the terrain. The 10-h total rainfall in the NTRN run revealed not only a lower amount near the front but also no rain along the coast of central Taiwan (Fig. 21). Rainfall over northwestern Taiwan was likewise produced after the front made landfall. The rain over land south of $24.3^{\circ} \mathrm{N}$ was displaced farther eastward, and the total amount was also reduced compared to both the HTRN and FTRN runs. Clearly, this reduction in rainfall was due to the removal of the CMR and the associated lifting effect. When the landmass of Taiwan was farther removed (and replaced with water) in the NLND run, the total rainfall distribution was nearly the same as in the NTRN run, but the rain south of $24.3^{\circ} \mathrm{N}$ was reduced and displaced (mostly to the east of $121.5^{\circ} \mathrm{E}$, not shown). Apart from this, the evolution of the flow field including the shape of the mei-yu front and the associated weather differed very little between the NTRN and NLND runs (not shown).

Overall results of the NTRN and NLND runs suggest that the strengthening of the front and its subsequent weakening (in terms of $\zeta$ ), particularly at its southern section, were primarily a result of frontal forcing and the interaction with convective cells. The intensity of the front was reduced when the Taiwan terrain (or landmass) was removed. Likewise, the low-level convergence zone over southwestern Taiwan was much weaker and had a different orientation without the terrain. The above differences, together with the lack of terrain uplifting, led to significantly lower amount as well as incorrect spatial distribution of total rainfall produced from the event (Figs. 18-21).

\section{Discussion}

\section{a. Topographical effects on the convective line}

In section 5 , it was shown that the control (FTRN) experiment was both realistic and highly agreed with

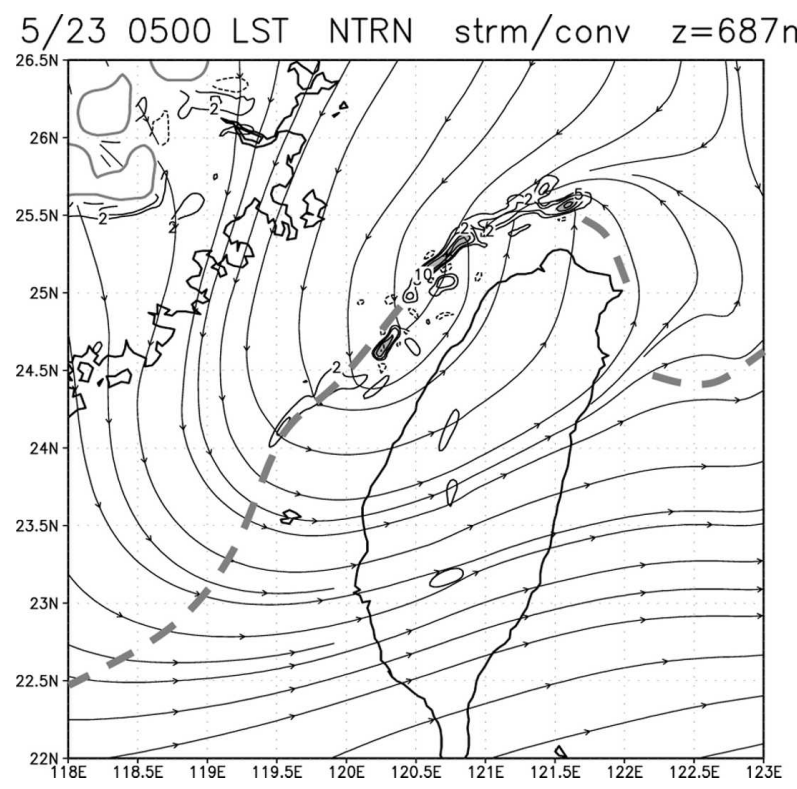

FIG. 19. Same as in Fig. 8, except for results in NTRN run at 0500 LST 23 May 2002. 
$5 / 230300$ LST NTRN u/v/q2max z=1006m

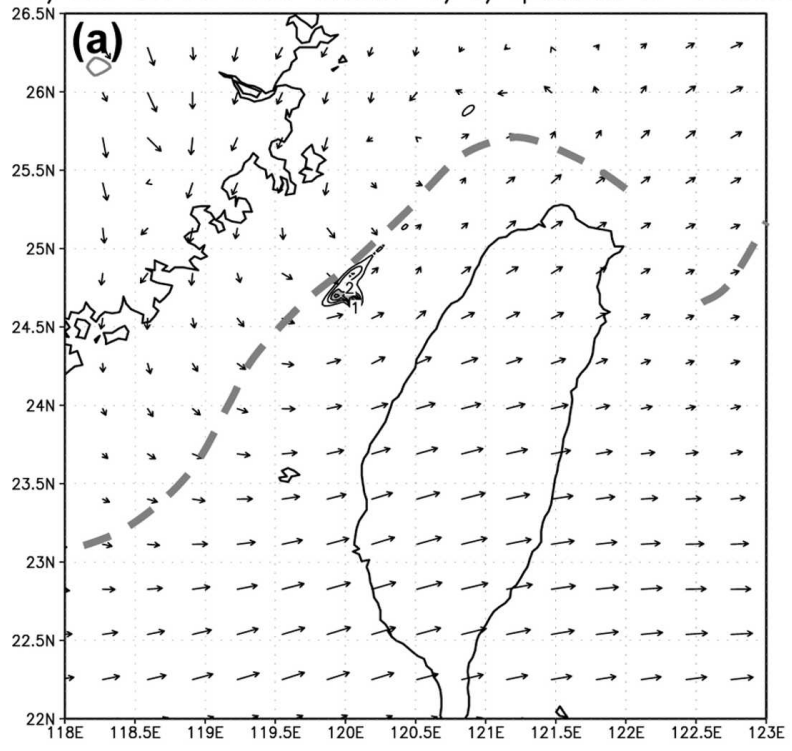

$5 / 230500$ LST NTRN u/v/q2max z=1006m

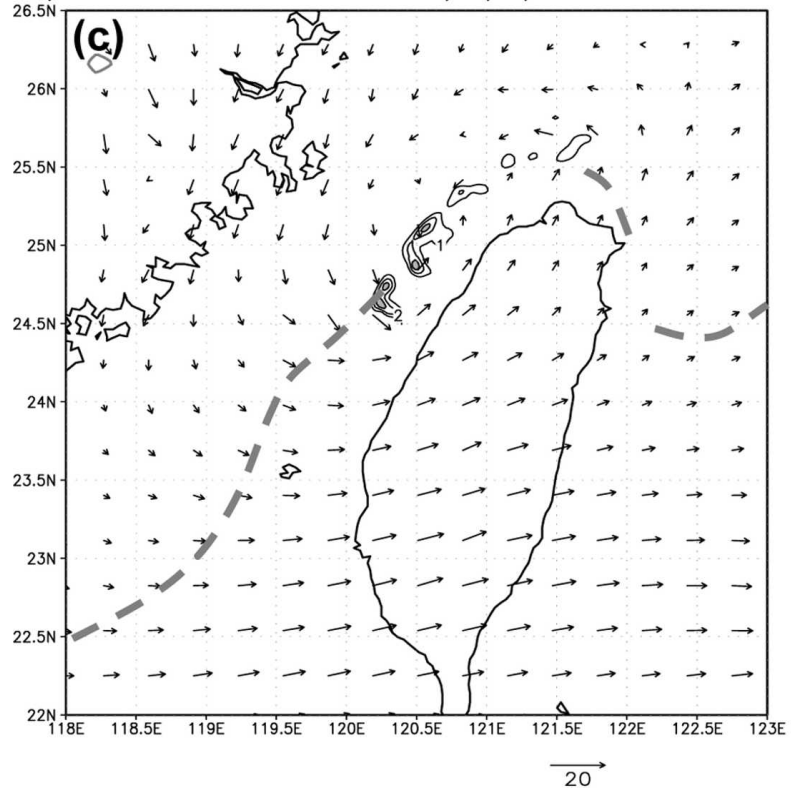

5/23 0400 LST NTRN u/v/q2max z=1006m

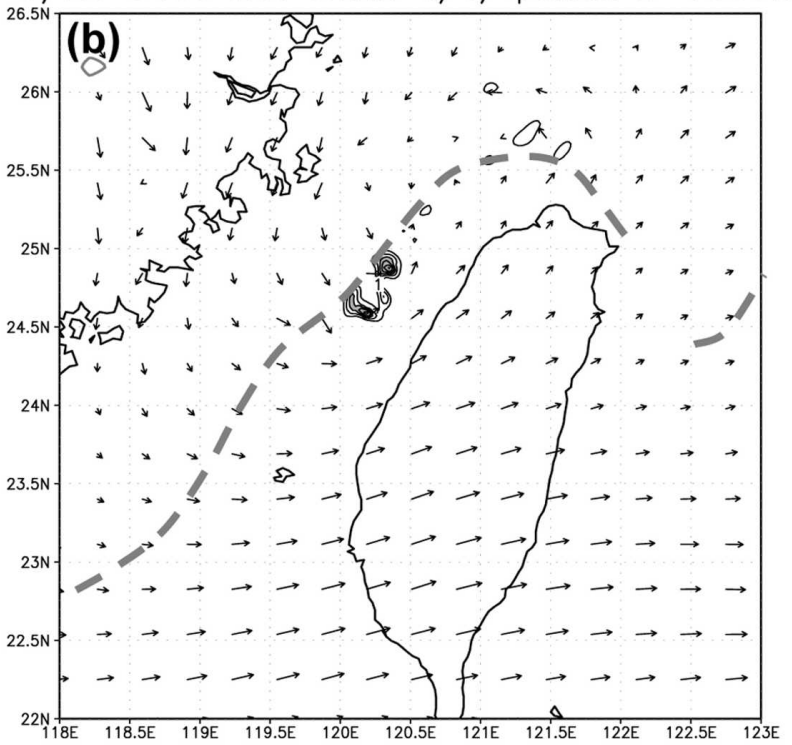

$5 / 230600$ LST NTRN u/v/q2max z=1006m

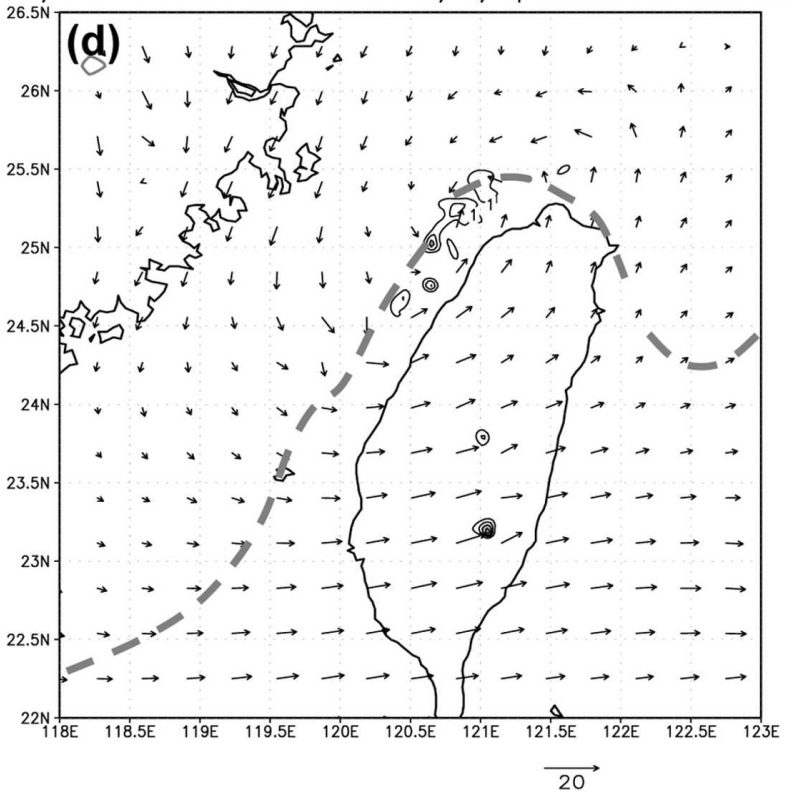

FIG. 20. Same as in Fig. 9, except for results in NTRN run at 1-h intervals from (a) 0300 to (d) 0600 LST 23 May 2002.

observations and previous studies (e.g., Wang et al. 1990; Lin et al. 1992; Akaeda et al. 1995). By comparing results of the FTRN and other runs, several topographical effects are identifiable. First and foremost, the northeast-southwest low-level convergence zone about $75 \mathrm{~km}$ off the coast was essential for the development of the convective line. Although being forced primarily by the mei-yu front, the convergence zone was weaker and slightly closer to Taiwan if the terrain was lowered or removed (Figs. 8, 14, and 19), a result in agreement with Yeh and Chen (2002). The weaker convergence caused a delay in the development of individual cells and affected their intensity and duration, thereby influencing the timing, amount, and distribution of rainfall over northwestern Taiwan (Figs. 9-10, 15-16, and 20-21). Due to terrain blocking, low-level pressure rose (fell) on the windward side (leeside) of the CMR to induce a dipole structure (with an amplitude of about $+1.0 /-1.8$ $\mathrm{hPa}$ ) after the FTRN run started (not shown), and this phenomenon was still evident at 0200 LST 23 May (Fig. 22a). Associated with this pressure pattern was an offshore wind component upstream of the CMR and a 
5/23 0000-1000 LST NTRN rainfall $(\mathrm{mm})$

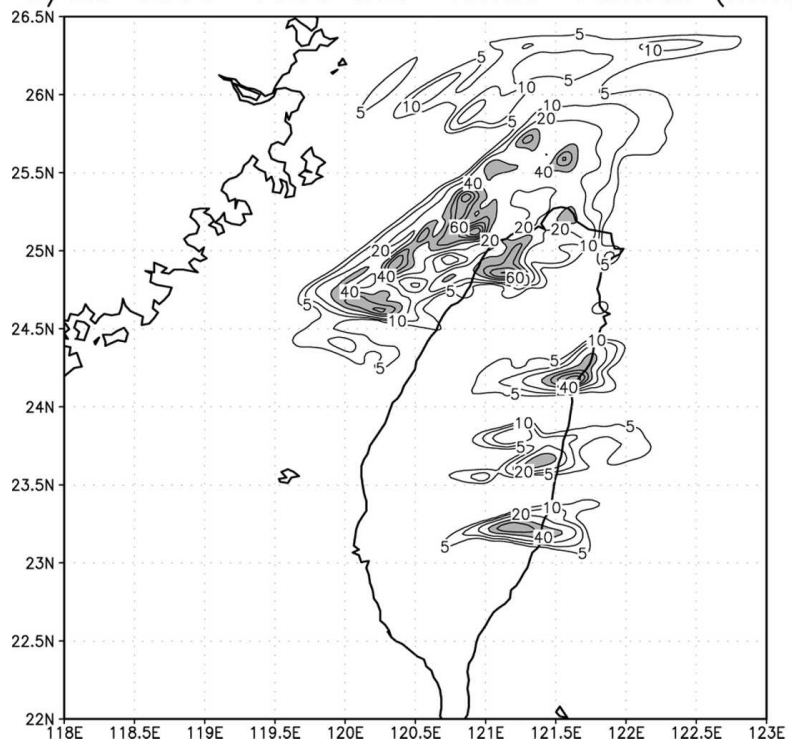

FIG. 21. Same as in Fig. 10, except for results in NTRN run.

cyclonic perturbation downstream. The offshore component gradually turned northward due to Coriolis acceleration and an alongshore pressure gradient, leading to intensification of southerly winds off northwestern Taiwan. At 0200 LST, the difference in southerly wind component between the FTRN and NTRN runs reached $7.5 \mathrm{~m} \mathrm{~s}^{-1}$, with additional flow convergence evident along the developing convective line. When a lower terrain was used, the pressure couplet induced was significantly weaker (about $+0.5 /-0.7 \mathrm{hPa}$ ) especially on the leeside (Fig. 22b). This is still consistent with theoretical expectation when Fr is increased from about 0.25 to 0.5 due to a reduction in $h$ (e.g., Blumen 1990; Baines 1995). The offshore flow component was also weaker, and the perturbed southerly winds only reached $5 \mathrm{~m} \mathrm{~s}^{-1}$ ahead of the front at 0200 LST (Fig. $22 \mathrm{~b})$. The second arc-shaped low-level convergence zone did not form in the NTRN experiment. Therefore, it is clear that the interaction between the prefrontal flow and topography instead of frontal forcing was responsible for its formation in the experiments with terrain. Its location was closer to the CMR in the HTRN run, which is also consistent with the weaker windwardside high and offshore flow perturbations. Thus, the second topographical effect was the formation of the arc-shaped convergence zone, which was closely related to the terrain and sensitive to its elevation.

Two additional effects related to the terrain could be identified. With a higher (lower) terrain, the shape of the vorticity zone associated with the mei-yu front experienced greater (less) distortion upon approaching northern Taiwan. A reduced terrain provided less me-
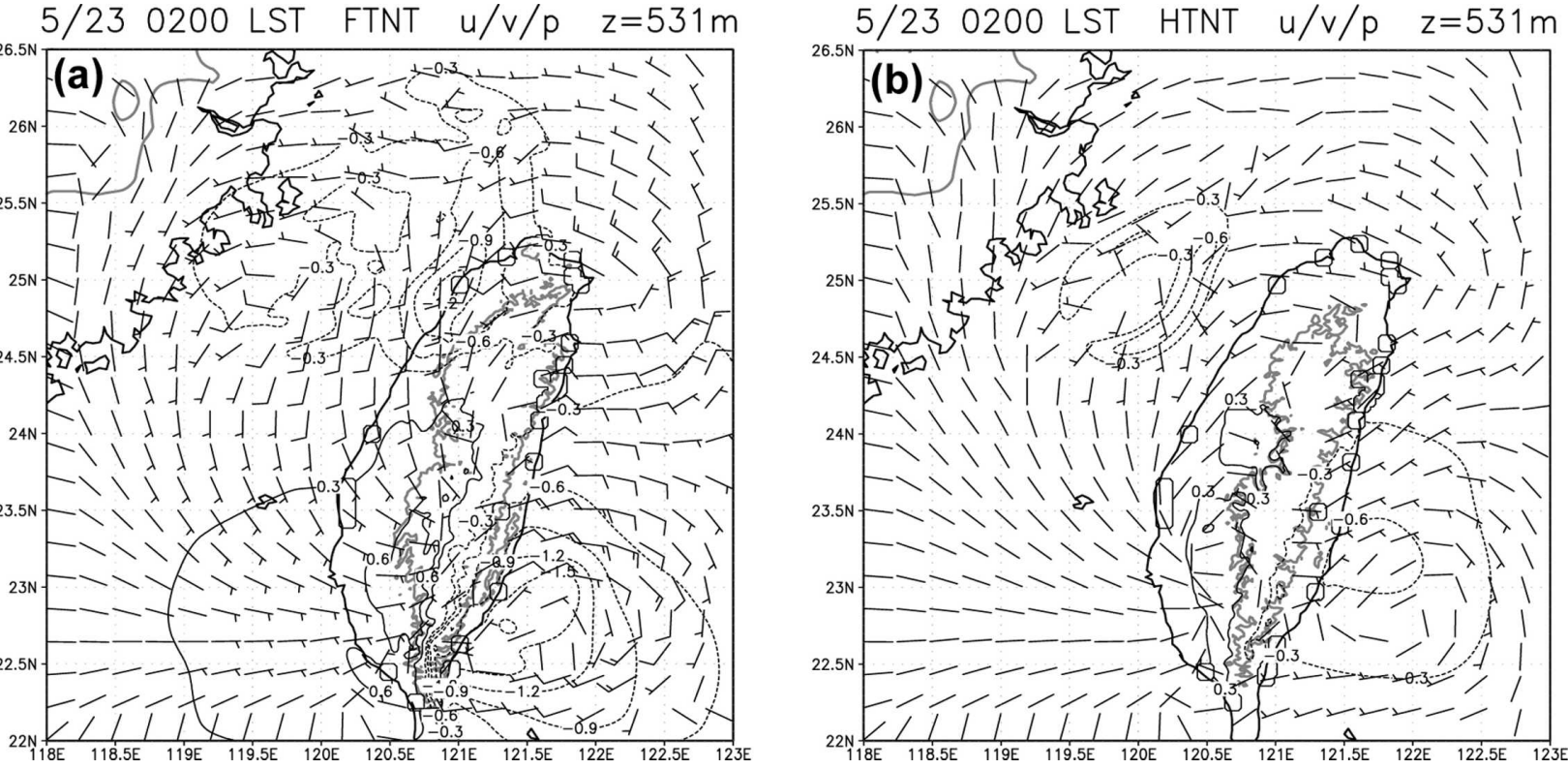

FIG. 22. (a) Difference between simulated horizontal wind $\left(\mathrm{m} \mathrm{s}^{-1}\right)$ and perturbation pressure (hPa) at $531 \mathrm{~m}$ in the FTRN and NTRN runs (FTRN - NTRN) at 0200 LST 23 May 2002. (b) Same as in (a), except for difference between HTRN and NTRN runs (HTRN - NTRN). For winds, full (half) barbs are $5(2.5) \mathrm{m} \mathrm{s}^{-1}$, and pressure is analyzed at 0.3 -hPa intervals with dashed lines for negative values and zero contour omitted. Thick gray line depicts $531-\mathrm{m}$ elevation in the run with a higher terrain, and the difference over areas with a surface higher than $531 \mathrm{~m}$ is for the lowest level above terrain with model output available. 

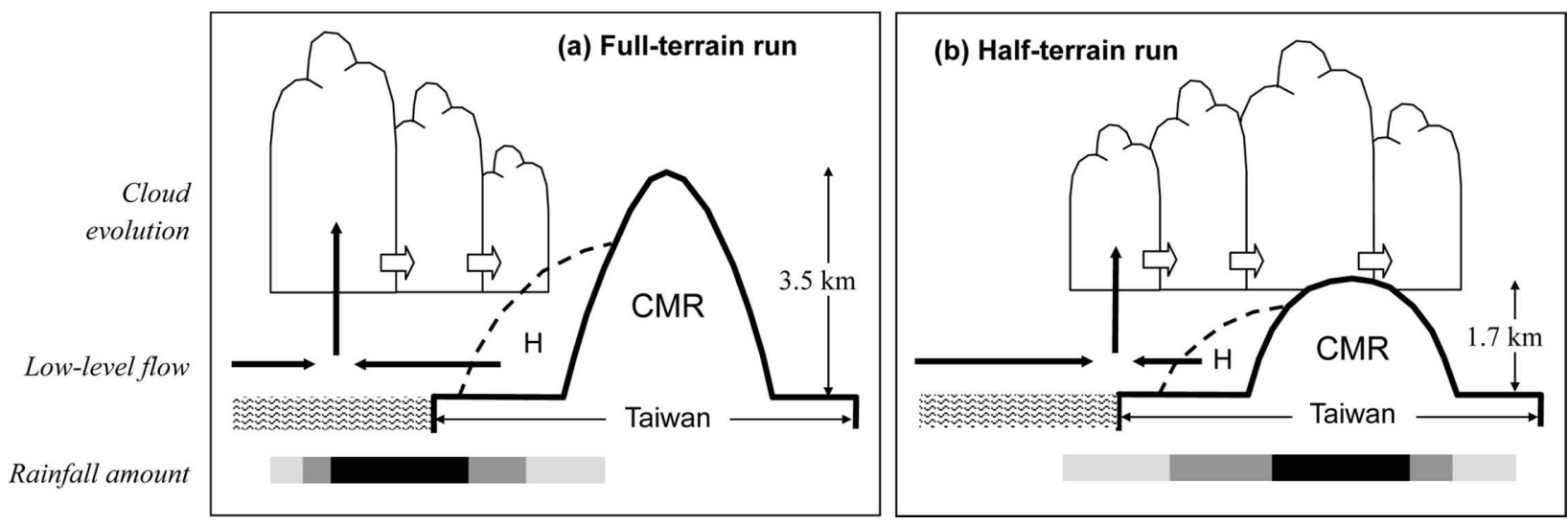

FIG. 23. Schematic illustration of topographical effects on low-level convergence, development of convection, and rainfall distribution near central Taiwan as simulated by the CReSS model using (a) the FTRN run and (b) the HTRN run. Shading indicates the amount and location of rainfall, with darker shade for greater amount.

chanical lifting when encountered by convective cells, and a smaller amount of rainfall was generally received (Figs. 10, 16, and 21). These findings are consistent with previous studies (Braun et al. 1997; Rotunno and Ferretti 2003; Medina and Houze 2003).

\section{b. Factors leading to coastal rainfall in central Taiwan}

In the FTRN run, the rainfall over the coastal region of central Taiwan was caused by convection that developed along the northern part of the arc-shaped convergence zone in the prefrontal environment (Figs. 9 and 10). Since this convergence zone was sensitive to terrain height as discussed, the correct rainfall pattern in central Taiwan did not occur in the HTRN run while the coastal rainfall was missing entirely in the NTRN run (Figs. 16 and 21). Thus, in our case, the terrain-induced convergence zone upstream from the CMR played a more important role than the terrain-enhanced frontal zone off northwestern Taiwan in determining the rainfall over central Taiwan. A schematic diagram comparing the results in sections 5 and $6 \mathrm{a}$ is presented to illustrate the role played by the terrain-induced low-level convergence in the FTRN run and the effects of a reduced terrain in the HTRN run (Fig. 23). In the FTRN run, $\mathrm{Fr} \approx 0.25$ and a stronger windward-side high was produced as the prevailing flow encountered the CMR. The induced low-level offshore flow was stronger, and a convergence zone formed farther upstream over the strait (Fig. 23a). The resultant convection reached peak intensity offshore, and the rainfall over land was maximized near the coast and decreased inland. In the HTRN run, as Fr increased to about 0.5 (Fig. 23b), terrain blocking still occurred but both the windward- side high and offshore flow were weaker. The resultant convergence zone was also weaker and located nearer the shoreline. The convection did not reach maturity until it moved upslope against the (reduced) CMR. As a result, maximum rainfall was received over the mountain instead of near the coast. These aspects were not discussed in detail by Yeh and Chen (2002), but were found to be vital here in the present case. Over many regions in northern Taiwan, the total rainfall received by 1000 LST 23 May 2002 was higher in both the HTRN and NTRN runs than in the FTRN run. This was mainly because the front moved farther inland when the terrain was reduced or removed, which is also consistent with earlier studies (Braun et al. 1997; Neiman et al. 2004). Other aspects such as the diabatic effect and the effect of precipitation on stability and blocking are also interesting, but not elaborated in the present study.

\section{Conclusions}

During 23 May 2002, a mei-yu front passed through Taiwan and the associated convective line brought heavy rainfall to the coastal region of centralnorthwestern Taiwan. Under favorable environmental conditions of large CAPE values (over $3000 \mathrm{~m}^{2} \mathrm{~s}^{-2}$ ) and warm air advection, deep convection broke out and was organized into a linear shape with a northeastsouthwest orientation along the front at about $70 \mathrm{~km}$ offshore from northwestern Taiwan. High-resolution experiments using the CReSS model were performed with different terrain heights (full, half, and no terrain), and the roles of Taiwan topography on this convective line and the subsequent rainfall distribution were investigated. The model results agreed very well with observations and revealed detailed interactions between the 
front, prefrontal flow, terrain, and convection in this case. The major findings can be summarized below.

1) The northeast-southwest-oriented low-level convergence zone at the leading edge of the mei-yu front was primarily caused by frontal forcing but enhanced by additional convergence induced by terrain blocking. The convergence about $75 \mathrm{~km}$ off the northwestern coast of Taiwan was between the northward-deflected flow and undisturbed southwesterly flow farther upstream, which is in agreement with previous studies. When the terrain was reduced in the model, the frontal convergence was weaker. Convective cells along the line were also shorter lived and delayed in their development, causing in general a smaller rainfall amount along the northwestern coast.

2) As the mei-yu front approached Taiwan, a second arc-shaped low-level convergence zone with a north-south orientation formed along about $120^{\circ} \mathrm{E}$ south of the front. This convergence zone was between the prefrontal southwesterly flow and the terrain-induced offshore flow near the surface from the southern CMR. This convergence zone also initiated a series of convective cells, and the convection near its northern end was directly responsible for the rainfall maximum along the coast of central Taiwan when moving onshore. In the half-terrain simulation, this second convergence zone was weaker and closer to the mountain due to an increase in $\mathrm{Fr}$, and the resultant rainfall was mostly over the mountain rather than near the coast. These findings are illustrated in a schematic diagram in Fig. 23.

3) The shape of the front near northern Taiwan was less distorted and the front could move farther inland in model simulations with the terrain reduced or removed. This yielded a higher rainfall amount in many regions over northern Taiwan during the later stages of the event.

Acknowledgments. The authors thank two anonymous reviewers for their constructive comments that helped improve the content and presentation of the manuscript, and the Central Weather Bureau of Taiwan for providing radar maps and rainfall data. Appreciation also goes to Mr. A. Sakakibara for his expertise and continuous help with the CReSS model, to Dr. Kevin Cheung at National Science and Technology Center for Disaster Reduction (NCDR) of Taiwan for proofreading the manuscript, and to Mr. J.-S. Yang for drafting Fig. 5. This study is supported by the National Science Council of Taiwan under Grants NSC-93-2111M-002-009 and NSC-93-2111-M-002-010.

\section{REFERENCES}

Akaeda, K., J. Reisner, and D. Parsons, 1995: The role of mesoscale and topographically induced circulations in initiating a flash flood observed during the TAMEX project. Mon. Wea. Rev., 123, 1720-1739.

Akiyama, T., 1973: The large-scale aspects of the characteristic features of Baiu front. Pap. Meteor. Geophys., 24, 157-188.

Asselin, R., 1972: Frequency filter for time integrations. Mon. Wea. Rev., 100, 487-490.

Baines, P. G., 1995: Topographic Effects in Stratified Flows. Cambridge University Press, 482 pp.

Banta, R. M., 1990: The role of mountain flows in making clouds. Atmospheric Processes over Complex Terrain, Meteor. Monogr., No. 45, Amer. Meteor. Soc., 229-284.

Bluestein, H. B., and M. H. Jain, 1985: Formation of mesoscale lines of precipitation: Severe squall lines in Oklahoma during the spring. J. Atmos. Sci., 42, 1711-1732.

Blumen, W., Ed., 1990: Atmospheric Processes over Complex Terrain. Meteor. Monogr., No. 45, Amer. Meteor. Soc., 323 pp.

Bousquet, O., and B. F. Smull, 2003: Observations and impacts of upstream blocking during a widespread orographic precipitation event. Quart. J. Roy. Meteor. Soc., 129, 391-409.

Braun, S. A., R. A. Houze Jr., and B. F. Smull, 1997: Airborne dual-Doppler observations of an intense frontal system approaching the Pacific Northwest coast. Mon. Wea. Rev., 125, 3131-3156.

Browning, K. A., 1990: Organization of clouds and precipitation in extratropical cyclones. Extratropical Cyclones: The Erik Palmén Memorial Volume, C. W. Newton and E. O. Holopanien, Eds., Amer. Meteor. Soc., 129-153.

Carbone, R. E., 1982: A severe frontal rainband. Part I: Stormwide hydrodynamic structure. J. Atmos. Sci., 39, 258-279.

Chen, G. T.-J., 1992: Mesoscale features observed in the Taiwan Mei-Yu season. J. Meteor. Soc. Japan, 70, 497-516.

_ and C. P. Chang, 1980: The structure and vorticity budget of an early summer monsoon trough (Mei-Yu) over southeastern China and Japan. Mon. Wea. Rev., 108, 942-953.

- , and H.-C. Chou, 1993: General characteristics of squall lines observed in TAMEX. Mon. Wea. Rev., 121, 726-733.

Chien, F.-C., C. F. Mass, and P. J. Neiman, 2001: An observational and numerical study of an intense landfalling cold front along the northwest coast of the United States during COAST IOP 2. Mon. Wea. Rev., 129, 934-955.

Colle, B. A., B. F. Smull, and M.-J. Yang, 2002: Numerical simulations of a landfalling cold front observed during COAST: Rapid evolution and responsible mechanisms. Mon. Wea. Rev., 130, 1945-1966.

Cotton, W. R., G. J. Tripoli, R. M. Rauber, and E. A. Mulvihill, 1986: Numerical simulation of the effects of varying ice crystal nucleation rates and aggregation processes on orographic snowfall. J. Climate Appl. Meteor., 25, 1658-1680.

Courtier, P., J.-N. Thepaut, and A. Hollingsworth, 1994: A strategy for operational implementation of 4-D-VAR using an incremental approach. Quart. J. Roy. Meteor. Soc., 120, 13671388.

Doyle, J. D., 1997: The influence of mesoscale orography on a coastal jet and rainband. Mon. Wea. Rev., 125, 1465-1488.

Grossman, R. L., and D. R. Durran, 1984: Interaction of low-level flow with the Western Ghat Mountains and offshore convection in the summer monsoon. Mon. Wea. Rev., 112, 652-672. Houze, R. A., Jr., B. F. Smull, and P. Dodge, 1990: Mesoscale 
organization of springtime rainstorms in Oklahoma. Mon. Wea. Rev., 118, 613-654.

Ikawa, M., and K. Saito, 1991: Description of a nonhydrostatic model developed at the Forecast Research Department of the MRI. MRI Tech. Rep. 28, 238 pp.

Kanamitsu, T., K. Tada, T. Kudo, N. Sato, and S. Isa, 1983: Description of the JMA operational spectral model. J. Meteor. Soc. Japan, 61, 812-828.

Kato, K., 1985: On the abrupt change in the structure of the Baiu front over the China continent in late May of 1979. J. Meteor. Soc. Japan, 63, 20-35.

Klemp, J. B., and R. B. Wilhelmson, 1978: The simulation of three-dimensional convective storm dynamics. J. Atmos. Sci., 35, 1070-1096.

Kondo, J., 1976: Heat balance of the China Sea during the air mass transformation experiment. J. Meteor. Soc. Japan, 54, 382-398.

Kuo, Y.-H., and G. T.-J. Chen, 1990: The Taiwan Area Mesoscale Experiment: An overview. Bull. Amer. Meteor. Soc., 71, 488503.

LeMone, M. A., E. J. Zipser, and S. B. Trier, 1998: The role of environmental shear and thermodynamic conditions in determining the structure and evolution of mesoscale convective systems during TOGA COARE. J. Atmos. Sci., 55, 34933518.

Li, J., and Y.-L. Chen, 1998: Barrier jets during TAMEX. Mon. Wea. Rev., 126, 959-971.

Lin, Y.-J., R. W. Paskin, and H.-W. Chang, 1992: The structure of a subtropical prefrontal convective rainband. Part I: Mesoscale kinematic structure determined from dual-Doppler measurements. Mon. Wea. Rev., 120, 1816-1836.

Lin, Y.-L., 1993: Orographic effects on airflow and mesoscale weather systems over Taiwan. Terr. Atmos. Ocean Sci., 4, 381-420.

— , R. D. Farley, and H. D. Orville, 1983: Bulk parameterization of the snow field in a cloud model. J. Climate Appl. Meteor., 22, 1065-1092.

Liu, A. Q., G. W. K. Moore, K. Tsuboki, and I. A. Renfrew, 2004: A high-resolution simulation of convective roll clouds during a cold-air outbreak. Geophys. Res. Lett., 31, L03101, doi:10.1029/2003GL018530.

Louis, J. F., M. Tiedtke, and J. F. Geleyn, 1981: A short history of the operational PBL parameterization at ECMWF. Proc. Workshop on Planetary Boundary Layer Parameterization, Reading, United Kingdom, ECMWF, 59-79.

Medina, S., and R. A. Houze Jr., 2003: Air motions and precipitation growth in alpine storms. Quart. J. Roy. Meteor. Soc., 129, 345-371.

Mellor, G. L., and T. Yamada, 1974: A hierarchy of turbulent closure models for planetary boundary layers. J. Atmos. Sci., 31, 1791-1806.

Murakami, M., 1990: Numerical modeling of dynamical and microphysical evolution of an isolated convective cloud-The 19 July 1981 CCOPE cloud. J. Meteor. Soc. Japan, 68, 107128.

, T. L. Clark, and W. D. Hall, 1994: Numerical simulations of convective snow clouds over the Sea of Japan: Twodimensional simulation of mixed layer development and convective snow cloud formation. J. Meteor. Soc. Japan, 72, 4362.

Neiman, P. J., P. O. G. Persson, F. M. Ralph, D. P. Jorgensen, A. B. White, and D. E. Kingsmill, 2004: Modification of fronts and precipitation by coastal blocking during an intense landfalling winter storm in southern California: Observations during CALJET. Mon. Wea. Rev., 132, 242-273.

Oh, J.-H., K. Tsuboki, T.-H. Kim, and D.-Y. Kang, 2004: Numerical simulation of a strong wind event occurred by typhoon 'Maemi' during Sep. 12-13, 2003. Proc. First Annual Meeting, Singapore, Asia Oceania Geosciences Society, 539-540.

Onogi, K., 1998: A data quality control method using horizontal gradient and tendency in a NWP system: Dynamic QC. $J$. Meteor. Soc. Japan, 76, 497-516.

Overland, J. E., and B. A. Bond, 1995: Observations and scale analysis of a coastal wind jet. Mon. Wea. Rev., 123, 29342941.

Pierrehumbert, R. T., 1984: Linear results on the barrier effects of mesoscale mountains. J. Atmos. Sci., 41, 1356-1367.

- and B. Wyman, 1985: Upstream effects of mesoscale mountains. J. Atmos. Sci., 42, 977-1003.

Richard, E., S. Cosma, P. Tabary, J.-P. Pinty, and M. Hagen, 2003: High-resolution numerical simulations of the convective system observed in the Lago Maggiore area on 17 September 1999 (MAP IOP 2a). Quart. J. Roy. Meteor. Soc., 129, $543-$ 563.

Rotunno, R., and R. Ferretti, 2003: Orographic effects on rainfall in MAP cases IOP 2b and IOP 8. Quart. J. Roy. Meteor. Soc., 129, 373-390.

Segami, A., K. Kurihara, H. Nakamura, M. Ueno, I. Takano, and Y. Tatsumi, 1989: Operational mesoscale weather prediction with Japan Spectral Model. J. Meteor. Soc. Japan, 67, 907923.

Smith, R. B., 1982: Synoptic observations and theory of orographically disturbed wind and pressure. J. Atmos. Sci., 39, 60-70.

Smolarkiewicz, P. K., R. M. Rasmussen, and T. L. Clark, 1988: On the dynamics of Hawaiian cloud bands: Island forcing. J. Atmos. Sci., 45, 1872-1905.

Steiner, M., O. Bousquet, R. A. Houze Jr., B. F. Smull, and M. Mancini, 2003: Airflow within major alpine river valleys under heavy rainfall. Quart. J. Roy. Meteor. Soc., 129, 411-431.

Trier, S. B., and D. B. Parsons, 1995: Updraft dynamics within a numerically simulated subtropical rainband. Mon. Wea. Rev., 123, 39-58

Tsuboki, K., 2004: High-resolution modeling of localized heavy rain associated with mesoscale convective systems during the Baiu season. Proc. First Annual Meeting, Singapore, Asia Oceania Geosciences Society, 517-518.

_ and A. Sakakibara, 2001: CReSS user's guide (in Japanese). 2 d ed. 210 pp.

_ , and —_, 2002: Large-scale parallel computing of cloud resolving storm simulator. High Performance Computing, H. P. Zima et al., Eds., Springer, 243-259.

Tsuyuki, T., and T. Fujita, Eds., 2002: Outline of the operational numerical weather prediction at the Japanese Meteorological Agency. JMA, 157 pp.

Wang, C.-C., and G. T.-J. Chen, 2003: On the formation of leeside mesolows under different Froude number flow regime in TAMEX. J. Meteor. Soc. Japan, 81, 339-365.

Wang, T.-C. C., Y.-J. Lin, R. W. Paskin, and H. Shen, 1990: Characteristics of a subtropical squall line determined from TAMEX dual-Doppler data. Part I: Kinematic structure. $J$. Atmos. Sci., 47, 2357-2381.

Yeh, H.-C., and Y.-L. Chen, 2002: The role of offshore convergence on coastal rainfall during TAMEX IOP 3. Mon. Wea. Rev., 130, 2709-2730. 